\title{
Evaluation of Exposures and Respiratory Health at a Rubber Manufacturing Facility
}

Report No. 2016-0227-3364

October 2019

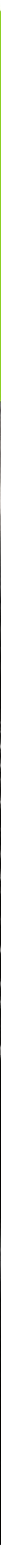

Suzanne E. Tomasi, DVM, MPH, DACVPM Ju-Hyeong Park, ScD, MPH, CIH Randall J. Nett, MD, MPH Stephen B. Martin, Jr, PhD, PE Rachel L. Bailey, DO, MPH Jean M. Cox-Ganser, PhD 


\section{Contents}

Highlights. i

Abbreviations .........................................vv

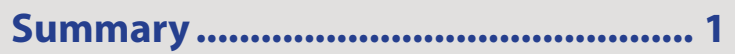

Introduction ........................................ 3

Background............................................... 3

Process Description ............................... 4

Methods .................................................... 5

Results ........................................... 11

Discussion ........................................... 16

Conclusions ........................................... 21

Recommendations........................... 22

Appendix A: Tables.............................. 25

References........................................... 48

Acknowledgements......................... 59

The employer is required to post a copy of this report for 30 days at or near the workplace(s) of affected employees. The employer must take steps to ensure that the posted report is not altered, defaced, or covered by other material.

The cover photo is a close-up image of sorbent tubes, which are used by the HHE Program to measure airborne exposures. This photo is an artistic representation that may not be related to this Health Hazard Evaluation. 


\section{Highlights of this Evaluation}

The Health Hazard Evaluation Program of the National Institute for Occupational Safety and Health received a confidential request from employees of a rubber manufacturing facility regarding concerns about exposure to and respiratory health effects from rubber manufacturing emissions and excessive heat during production.

\section{What We Did}

- We visited the rubber manufacturing facility during January 31-February 1, 2017 , to tour the facility, observe employees performing tasks, and learn about the rubber manufacturing process.

- During the visit we:

- Measured real-time air levels of total particulates for mass and concentration, total volatile organic compounds, carbon monoxide, carbon dioxide, temperature, and relative humidity.

- Collected integrated air samples for identifying and quantifying individual volatile organic compounds.

- Informally interviewed randomlyselected employees.

- Reviewed the safety data sheets.

- Met with management and employee representative.

- We conducted 11 information sessions with management and employees to discuss employee concerns and describe the medical survey during May 9-10, 2017.

- We conducted a medical survey during June 5-16, 2017, that included a health questionnaire, breathing tests, and blood draws.

- We performed a qualitative ventilation assessment during March 5-8, 2018, to evaluate the local exhaust ventilation systems associated with rubber production.

We evaluated potential respiratory exposures during production and the respiratory health of employees at a rubber manufacturing facility. More than 90 volatile organic compounds were identified from 10 locations using integrated sampling. Two hundred sixty-nine (74\%) participants reported at least one upper respiratory symptom in the past 12 months, and 160 (59\%) of these participants reported their symptoms improved when away from work or something at work aggravated the symptoms. Participating employees were 2.5 times more likely to reported wheezing or whistling in their chest compared with the U.S. general population. Participants were 1.3 times more likely to report stuffy, itchy, or runny nose and 1.5 times more likely to report shortness of breath on level ground compared with the U.S. general population. Participants working in extrusion were 1.8 times more likely to report workrelated upper respiratory symptoms and 3.7 times more likely to report workrelated breathing trouble compared with participants from non-production departments. Participants working in mixing were 2.8 time more likely to report workrelated upper respiratory symptoms, 4.3 times more likely to report work-related usual cough, and 4.1 times more likely to report trouble with phlegm compared with participants from non-production departments. There was not an excess of spirometry abnormalities in comparison with the general U.S. population. Overall, the local exhaust ventilation systems throughout the facility provided good capture of released contaminants with the exception of the canopy hoods. We recommend limiting employee exposures to rubber manufacturing emissions by ensuring all ventilation units are functioning properly. Because participants in extrusion, finishing, and mixing had higher prevalences of respiratory symptoms, we recommend implementing a medical surveillance program for employees who work in extrusion, finishing, or mixing. We also recommend health and safety infographics and translating health and safety communication materials to common languages spoken at the facility. 


\section{What We Found}

- During the January 31-February 1, 2017 visit:

- Sixteen (18\%) of 88 employees informally interviewed reported current respiratory symptoms that improve away from work; nine (10\%) participants reported concerns about excessive heat in the production areas during the summer months.

- Health and safety communication materials posted in English when approximately one-third of the employees were non-native English speakers.

- Spot measurements of submicron particulates using a real-time particle counter exceeded 500,000 particles per cubic centimeter in 56\% of the extrusion and production areas sampled. No occupational exposure limits for submicron particulates have been established.

- A spot measurement of carbon monoxide concentration higher than 30 parts per million in the long breezeway between the warehouse and manufacturing area.

- We detected 96 volatile organic compounds from the integrated air samples.

- During the June 5-16, 2017 medical survey:

- Of the 649 employees reported on the employee roster, 365 employees participated in the medical survey.

- Two hundred sixty-nine (74\%) participants reported at least one upper respiratory symptom in the past 12 months, and 160 (59\%) of these participants reported their symptoms improved when away from work or something at work aggravated the symptoms.

- Two hundred twenty-nine (63\%) participants reported at least one lower respiratory symptom in the past 12 months, and 103 (45\%) of these participants reported their symptoms improved when away from work.

- Participants were 2.5 times more likely to report wheezing or whistling in the chest in the last 12 months compared with the U.S. general population.

- Participants were 1.5 times more likely to report shortness of breath on level ground and 1.3 times more likely to report stuffy, itchy, or runny nose compared with the U.S. general population.

- Compared with participants from non-production departments, participants working in extrusion were 1.8 times more likely to report work-related upper respiratory symptoms and 3.7 times more likely to report work-related breathing trouble.

- Compared with participants from non-production departments, participants working in mixing were 2.8 times more likely to report work-related upper respiratory symptoms, 4.3 times more likely to report work-related usual cough, and 4.1 times more likely to report trouble with phlegm.

- Most (89\%) spirometry tests were normal; 25 (7\%) spirometry tests were interpreted as having a restrictive pattern, seven $(2 \%)$ an obstructive pattern, and two (1\%) a mixed pattern

- During the March 5-8, 2018 ventilation visit:

- Most of the local exhaust ventilation systems throughout the plant, including all spray booths, provided good capture of released contaminants.

- Generally, the canopy hoods were the poorest performing local exhaust ventilation capture points in the facility due to excessive vertical distance between the rubber production lines and canopy hood openings. 


\section{What the Employer Can Do}

- Ensure employees understand potential health effects in the workplace and how to protect themselves.

- Provide health and safety communication materials in infographics or common languages spoken at the facility.

- Encourage employees to report new, worsening, or ongoing respiratory symptoms to a designated individual at the workplace and their personal healthcare providers.

- Implement a medical surveillance program for employees who work in extrusion, finishing, or mixing.

- Make sure all ventilation units are functioning properly.

- Continue to properly maintain a negative pressure in the production area relative to the adjacent nonproduction spaces (including the break room) as future ventilation and production line modifications are made.

\section{What Employees Can Do}

- Report new, persistent, or worsening respiratory symptoms to your personal healthcare provider(s) and a designated individual at your workplace.

- Participate in your employer's medical surveillance program as instructed by your employer.

- Report ventilation problems to a designated individual at your workplace.

- If you smoke, participate in a smoking cessation program. 
This page left intentionally blank 


\section{Abbreviations}

\begin{tabular}{|c|c|}
\hline$\mu \mathrm{m}$ & Micrometer \\
\hline $\mathrm{ACGIH}^{\oplus}$ & American Conference of Governmental Industrial Hygienists \\
\hline $\mathrm{APF}$ & Assigned protection factor \\
\hline $\mathrm{AX}$ & Total reactance \\
\hline CBC & Complete blood count \\
\hline $\mathrm{cc} / \mathrm{min}$ & Cubic centimeters per minute \\
\hline CFR & Code of Federal Regulations \\
\hline $\mathrm{CI}$ & Confidence interval \\
\hline $\mathrm{cm} \mathrm{H} 2 \mathrm{O} / \mathrm{L} / \mathrm{s}$ & Centimeters of water per liter per second \\
\hline $\mathrm{CO}$ & Carbon monoxide \\
\hline $\mathrm{CO}_{2}$ & Carbon dioxide \\
\hline COPD & Chronic obstructive pulmonary disease \\
\hline $\mathrm{CV}$ & Continuous vulcanization \\
\hline EPDM & Ethylene propylene diene monomer \\
\hline EPA & Environmental Protection Agency \\
\hline FEV1 & Forced expiratory volume in one second \\
\hline FENO & Fractional exhaled nitric oxide \\
\hline FVC & Forced vital capacity \\
\hline IOS & Impulse oscillometry \\
\hline $\mathrm{kPa} /(\mathrm{L} / \mathrm{s})$ & Kilopascals per liter per second \\
\hline LEV & Local exhaust ventilation \\
\hline $\mathrm{mg} / \mathrm{m}^{3}$ & Milligrams per cubic meter of air \\
\hline $\mathrm{mL} / \mathrm{min}$ & Milliliter per minute \\
\hline NAICS & North American Industry Classification System \\
\hline NHANES & National Health and Nutrition Examination Survey \\
\hline NIOSH & National Institute for Occupational Safety and Health \\
\hline OEL & Occupational exposure limit \\
\hline OSHA & Occupational Safety and Health Administration \\
\hline PEL & Permissible exposure limit \\
\hline PFT & Pulmonary function testing \\
\hline ppb & Parts per billion \\
\hline ppm & Parts per million \\
\hline R5 & Resistance at 5 Hertz \\
\hline R5-20 & Frequency dependence of resistance \\
\hline $\mathrm{R} 20$ & Resistance at 20 Hertz \\
\hline REL & Recommended exposure limit \\
\hline SD & Standard deviation \\
\hline SDM & Sponge dense metal \\
\hline
\end{tabular}




$\begin{array}{ll}\text { SMR } & \text { Standard morbidity ratio } \\ \text { SOB } & \text { Shortness of breath } \\ \text { STEL } & \text { Short-term exposure limit } \\ \text { TD } & \text { Thermal desorption } \\ \text { TLV }^{\circledR} & \text { Threshold limit value } \\ \text { TVOC } & \text { Total volatile organic compounds } \\ \text { TWA } & \text { Time-weighted average } \\ \text { U.S. } & \text { United States } \\ \text { VOC } & \text { Volatile organic compounds } \\ \text { X5 } & \text { Reactance at 5 Hertz } \\ \text { R20 } & \text { Resistance at 20 Hertz } \\ \text { REL } & \text { Recommended exposure limit } \\ \text { SMR } & \text { Standardized morbidity ratios } \\ \text { RH } & \text { Relative humidity } \\ \text { STEL } & \text { Short-term exposure limit } \\ \text { TLV } & \text { Threshold limit value } \\ \text { TWA } & \text { Time-weighted average } \\ \text { VOC } & \text { Volatile organic compound } \\ \text { X5 } & \text { Reactance at } 5 \text { Hertz }\end{array}$




\section{Summary}

In August 2016, the National Institute for Occupational Safety and Health received a confidential request from employees at a rubber manufacturing facility about exposure to and respiratory health effects from rubber manufacturing emissions and excessive heat during production.

In January 2017, we conducted an initial site visit. During this visit, we toured the facility, observed employees performing various tasks, measured total particulate matter and submicron particulate (aerodynamic diameter less than one micrometer), measured total volatile organic compounds and carbon monoxide, performed quantitative and semiquantitative screening of specific volatile organic compounds, conducted a walk-through of the ventilation system, and interviewed 88 randomly selected employees from each department. Sixteen (18\%) of 88 employees interviewed reported current respiratory symptoms that improve away from work; nine (10\%) participants reported concerns about excessive heat in the production areas during the summer months. Real-time tests demonstrated high concentrations of ultrafine particles (exceeding the instrument range of 500,000 particles per milliliter) in most of the extrusion and production areas. The qualitative ventilation assessment identified areas where ventilation could be improved. We detected 96 volatile organic compounds. Sixteen (18\%) of 88 employees reported current respiratory symptoms that improve away from work. Based on the real-time monitoring and ventilation assessment during the site visit and the possibility of work-related respiratory problems identified during the informal interviews, we conducted a medical survey and extensive ventilation assessment.

In May 2017, we conducted 11 onsite information sessions with management and employees to discuss employee concerns and describe the medical survey. In June 2017, we offered a medical survey to all employees across shifts. We provided Arabic, Burmese, Spanish, and Vietnamese interpreters for employees who requested language assistance. The medical survey consisted of a health and work history questionnaire, lung function testing (spirometry, impulse oscillometry, and exhaled nitric oxide), and a blood sample for a complete blood count.

Of the 649 employees, 365 (56\%) participated in the medical survey. Of the 365 participants, $296(74 \%)$ reported one or more upper respiratory symptoms; $160(59 \%)$ of the 269 reported something at work aggravated their symptoms or their symptoms improved when away from work. Compared with the U.S. general population, participants were 2.5 times more likely to report wheezing or whistling in their chest, 1.5 times more likely to report shortness of breath on level ground, and 1.3 times more likely to report stuffy, itchy, or runny nose. Participants who reported working in extrusion were 3.7 times more likely to report workrelated breathing trouble and 1.8 times more likely to report work-related upper respiratory symptoms compared with the participants who reported working in non-production departments. Participants who reported working in mixing were 2.8 times more likely to report work-related upper respiratory symptoms, 4.3 times more likely to report work-related usual cough, and 4.1 times more likely to report trouble with phlegm compared with those who reported working in non-production departments. The mean medical test parameters for 
spirometry, impulse oscillometry, and exhaled nitric oxide were normal for all departments.

In March 2018, we conducted an assessment of the ventilation system using fog generators. Overall, the local exhaust ventilation systems throughout the plant provided significant capture of released contaminants. The canopy hoods consistently had the poorest capture of released contaminants, which allowed contaminants to escape into the production areas of the plant. This was most likely caused by the distance between the canopy hood and the rubber product (i.e., source of emissions) moving under the hood.

The respiratory symptoms and breathing test abnormalities observed among the medical survey participants are not specific to a particular respiratory problem or disease. Although we could not prove causal association between workplace exposure and respiratory symptoms, we found a higher than expected prevalence of wheeze, shortness of breath on level ground, and stuffy, itchy, or runny nose compared with the U.S. general population. Rubber manufacturing workers are exposed to a complex mixture of dust, gases, vapors, fumes, and chemical byproducts. Previous studies have indicated that mixed dust, gas, vapor, fume, and chemical exposures could alter the expected health effects of exposure to individual contaminants on the respiratory system. In this report, we summarize the results from our medical and industrial hygiene surveys and ventilation assessment. Additionally, we provided recommendations to help protect the health of employees. We previously mailed letters with interim results and recommendations in February, April, and June 2017 and April 2018. 


\section{Introduction}

In August 2016, the National Institute for Occupational Safety and Health (NIOSH) received a confidential employee request for a health hazard evaluation at a rubber manufacturing facility about exposure to and respiratory health effects from rubber manufacturing emissions and excessive heat during production. In January 2017, we conducted an initial site visit that included a walk-through of the ventilation system, limited industrial hygiene sampling, employee observations, and confidential interviews. During the visit, we observed employees performing various tasks and collected real-time monitoring data for total particulate matter and submicron particulate, total volatile organic compounds (TVOCs), and carbon monoxide (CO). We collected time-integrated air samples for identification of specific volatile organic compounds (VOCs). We also randomly selected employees from each department to interview. In May 2017, we conducted onsite informational sessions about the health hazard evaluation and NIOSH medical survey scheduled for June 2017. In June 2017, we conducted a medical survey at the company that included a health questionnaire, breathing tests, and blood draws. In March 2018, we performed a qualitative ventilation assessment to evaluate the local exhaust ventilation systems at the facility.

\section{Background}

Rubber products such as automobile tires and automotive moldings are produced by combining numerous synthetic and natural chemicals that are subjected to a series of reactions using heat, pressure, and catalysts in the manufacturing process [Governa et al. 1987; Gupta et al. 1993]. During the mixing, milling, extruding, and vulcanizing that occurs in the rubber manufacturing process, dusts, gases, vapors, fumes, and chemical byproducts, collectively referred to as rubber manufacturing emissions, are produced and released into the work environment [McMichael et al. 1976; Jonsson et al. 2008]. Occupational exposure to rubber manufacturing emissions occurs through inhalation or skin contact during the manufacturing process [McMichael et al. 1976; Zuskin et al. 1996; Meijer et al. 1998; Attarchi et al. 2013].

Work-related respiratory disease is common among the U.S. general population. Approximately $17 \%$ of all adult-onset asthma cases and $15 \%$ of chronic obstructive pulmonary disease (COPD) cases are associated with occupational exposures [Torén and Blanc 2009; Blanc 2012; Blanc et al 2019]. These work-related respiratory diseases have a substantial economic impact related to healthcare cost, absenteeism, and disability [Lednar et al. 1977; Moscato and Rampulla 2003].

Many of the compounds in rubber manufacturing emissions are known respiratory hazards (irritants or sensitizers) that can cause acute or chronic respiratory symptoms [Governa et al. 1987; Zuskin et al. 1996; Akca et al. 2011]. However, only a small proportion of the numerous chemicals found in rubber manufacturing emissions have Occupational Safety and Health Administration (OSHA) permissible exposure limits (PELs) or NIOSH recommended exposure limits (RELs). Additionally, exposure to different chemicals adsorbed on 
combustion-derived ultrafine particles can alter the expected health effects of the exposure to ultra-fine particles [Penn et al. 2005]. Because rubber manufacturing emissions are complex and vary by the ingredients, processing methods, and final products, studies have indicated a good ventilation system is the most effective method for reducing respiratory illness among rubber manufacturing employees [Bascom et al. 1990].

Previous studies have indicated inhaling fumes from heated synthetic chemicals can lead to the development of respiratory symptoms [Evans 1973; Kuntz and McCord 1974; Fine and Peter 1976a; Haponik and Summer 1981; Froneberg et al. 1982; Parkes 1983; Bascom et al. 1988]. Five cases of respiratory illness were identified among thermoinjection process employees at an automotive rubber manufacturing facility [Bascom et al. 1988]. Air sampling at the rubber manufacturing facility identified various components of the rubber manufacturing emissions including resins, catalysts, synthetic rubber, fillers; however, all samples were below applicable OSHA PELs. Bascom et al. determined the required maneuvers for the employee to complete their job tasks put the rubber manufacturing emission in the employees breathing zone [Bascom et al. 1988, 1990]. In addition to respiratory impairment, the five respiratory cases identified at this rubber manufacturing facility also had elevated blood eosinophil counts. Other studies have identified acute and chronic respiratory symptoms and lung function abnormalities among rubber manufacturing workers [Thapa et al. 2019].

\section{Process Description}

The facility produces automotive rubber and plastic weather stripping and had 649 employees at the time of the health hazard evaluation. The employees were not represented by a union. Production ran 24-hours a day with three eight-hour shifts with rotating start times. Most employees worked in production; roughly, one-quarter of employees were involved in administration tasks including accounting, quality control, human resources, purchasing, data processing, plant management, or product development. Although there were separate areas for extrusion, molding, and finishing, the facility's production area was mainly one large open room; some areas were separated by walls that did not completely reach the ceiling. The mixing area was in a separate room with its own ventilation system.

Rubber at this facility was produced from raw ingredients including ethylene propylene diene monomer (EPDM) rubber, carbon black, vulcanizing agents, and coatings. In the mixing area, employees used an ergonomic lifting apparatus to add blocks of EPDM rubber to the mix. In a separate room, employees measured out carbon black on a table with slot ventilation. Employees measured out other powdered ingredients on a ventilated table in the same room as the mixing process. Powdered ingredients were gradually being replaced with sheet and pellet materials. Raw black rubber material was produced in sheet or rope form. Ropes of rubber were produced using the Barwell extruder. "Pigs" of rolled-up rubber sheet material were fed into the Barwell extruder batch-wise. The ropes of rubber coming out of the Barwell extruder were coated with a non-stick spray to prevent sticking together before being wound onto spools. 
From the mixing area, the black rubber material moved to the extrusion area where two different types of extruders were used: continuous vulcanization (CV) and sponge dense metal (SDM). During these processes, CV extruders produced long hollow ropes of rubber weather-stripping; whereas, SDM extruders produced long rubber weather-stripping extruded directly onto a metal support in strip or mesh form. In addition, there was one extruder that produced material in wide, flat sheets. Two extruders produced plastic materials. These plastics were not cured.

Rubber from the CV and SDM extruders passed through a series of conventional ovens or microwaves that cure or vulcanize the material. The $\mathrm{CV}$ extruders were numbered from five to 13; CVs one through four had been removed. SDM lines were numbered from one to six (or EA through EF). SDM lines moved faster than CV lines; therefore, the SDM lines were longer to allow for the same amount of curing time. Every extruder line (both CV and SDM) except for SDM-3 (the oldest line) used hot air vulcanization. SDM-3 (or SDM EC) used glass bead vulcanization in beds of tiny, heated glass beads.

After the vulcanizing process, the rubber was cooled using air or a water bath. Sometimes, there were additional processing steps, such as hole punching, laser marking, plasma etching, or spray coating. Several different coatings were used in the CV lines. Several different coatings were used in the SDM lines. Coated rubber underwent another curing and cooling process.

Next the rubber went through a finishing process to be cut to length, and the ends were joined into a finished automotive seal product using a high-temperature molder. These joined areas were then sprayed by hand with a coating in a spray booth. In at least one area, robots were used to perform these finishing operations. The final products were sent to the onsite warehouse until shipped out.

\section{Methods}

We initially visited the rubber manufacturing facility in January 2017. We collected integrated area air samples, monitored real-time concentrations of particulates and TVOCs at selected locations, performed a walk-through of the ventilation system, and conducted informal interviews with employees. In May 2017, we conducted 11 onsite information sessions with management and employees to discuss employee concerns and describe the medical survey. We visited the facility again in June 2017 to conduct a medical survey that included a health questionnaire, breathing tests, and blood draws. We returned in March 2018 to perform an extensive ventilation assessment to evaluate the local exhaust ventilation systems associated with rubber production. We provided four interim reports.

\section{Initial Site Visit - January 2017}

During the initial site visit, we met with management and employee representatives to discuss the health hazard evaluation request and describe the objectives, activities, and sampling plan for our visit. We toured the facility and learned about the rubber manufacturing process. 
We observed employees performing various work tasks. We measured total particulate matter and submicron particulate, TVOCs, and CO concentrations in different locations using direct reading instruments. Using thermal desorption (TD) tubes, we collected time-integrated air samples to quantitatively and semi-quantitatively screen for specific VOCs in different locations. We used smoke tubes to evaluate the hoods in extrusion areas. We interviewed randomly selected employees from each department and reviewed Safety Data Sheets. At the conclusion of our site visit, we held a closing meeting with management and employees.

\section{Real-time Air Monitoring}

We measured total particulate matter, submicron particulate, TVOCs, $\mathrm{CO}$, and $\mathrm{CO}_{2}$ concentrations in ten locations using direct reading instruments. We used the DustTrak DRX (TSI, Shoreview, $\mathrm{MN}$ ) to measure total particulate matter and the P-Trak (TSI, Shoreview, MN) to measure submicron particulate. We used ppbRAE 3000 (RAE systems, San Jose, CA) monitors to measure real-time concentrations of TVOCs in the air to obtain general understandings of exposures to all VOCs and to utilize the results in determining ten locations for time-integrated sampling of individual VOCs. This sampling was conducted to better understand potential employee exposures to TVOCs. We performed spot measurements (10 second average) of TVOCs at every local exhaust ventilation hood in the extrusion line areas. We also measured $\mathrm{CO}, \mathrm{CO}_{2}$, temperature, and relative humidity using VelociCalc (TSI, Shoreview, MN).

\section{Time-integrated Air Sampling}

We performed time-integrated air sampling using TD tubes to characterize the mixture of unknown VOCs in the extrusion and production areas. We sampled 10 locations for VOCs with the TD tubes. We choose this location based on the possibility of escape of rubber manufacturing emissions from nearby exhaust hoods and the highest TVOCs measurements using the ppbRAE. We collected VOCs in the TD tubes with average flow rates of 29 milliliters $/$ minute ( $\mathrm{mL} / \mathrm{min}$ ) (range: $25 \mathrm{~mL} /$ $\mathrm{min}-30.5 \mathrm{~mL} / \mathrm{min}$ ) for more than six hours. VOCs captured in the sorbents (CarbopackTM and CarboxenTM) of the TD tubes were extracted and analyzed with a gas chromatograph-mass spectrometer based on NIOSH analytical method 2549 [NIOSH 1996]. TD tube sampling results provided the type of detected VOCs and quantitative concentrations for the VOCs listed in the U.S. Environmental Protection Agency (EPA) TO-17 methods [EPA 1999] and semi-quantitative results for other VOCs.

\section{Exposure Limits}

We utilize mandatory (legally enforceable) and recommended occupational exposure limits (OELs) when evaluating workplace hazards. OELs have been developed by federal agencies, and safety and health organizations to prevent adverse health effects from workplace exposures.

\section{Ventilation Assessment}

In January 2017, we used a smoke test tube to quickly evaluate all hoods during the walkthrough of the ventilation systems. We observed that there might be potential escape of rubber manufacturing emissions from many hoods. This observation resulted in more extensive assessment of ventilation in March 2018.

\section{Informal Employee Interviews}

Using a list of all current employees at the facility provided by management, we grouped 
employees by department and used SAS computer software to randomly select $25 \%$ of employees from each department to interview. The goal of the open-ended interview questions was to collect exposure and health concerns. We identified 113 employees to interview. To begin each interview, we reviewed a copy of the informational handout about the NIOSH visit and informed the employee that participating in the interview was voluntary and confidential.

\section{Medical Survey Scheduling Visit - May 2017}

During May 9-10, 2017, NIOSH conducted 11 onsite information sessions with management and all available employees to discuss the health hazard evaluation request and describe the scope of the medical survey. During these information sessions, employees had the opportunity to sign up for a medical survey appointment in June 2017 and request an interpreter in Arabic, Burmese, Spanish, Vietnamese, or Japanese.

\section{Medical Survey, June 2017}

\section{Participants}

All employees were invited to participate in the medical survey at the workplace during June 5-16, 2017. Participation was voluntary; written informed consent was obtained from each participant before beginning. The medical survey included, in the order performed, a medical and work history questionnaire, quantification of exhaled nitric oxide, impulse oscillometry, spirometry, and collection of a blood sample for a complete blood count. We mailed participants their individual reports explaining their breathing and blood test results and recommended each participant provide the information to their personal physician or healthcare provider.

\section{Questionnaire}

We used an interviewer-administered computerized questionnaire to ascertain symptoms and diagnoses, work history at this rubber manufacturing facility, and cigarette smoking history. Questions on respiratory health were derived from five standardized questionnaires, the European Community Respiratory Health Survey [Burney et al. 1994; ECRHS 2014], the American Thoracic Society adult respiratory questionnaire (ATS-DLD-78) [Ferris 1978], the International Union Against Tuberculosis and Lung Disease [Burney and Chinn 1987; Burney et al. 1989], and the Third National Health and Nutrition Examination Survey (NHANES III) [CDC 1996] and NHANES 2007 $\neg 2012$ questionnaires [CDC 2018a]. Some of the questions appeared on more than one of the standardized questionnaires. We also supplemented our questionnaire with additional respiratory and systemic symptom questions.

\section{Fractional Exhaled Nitric Oxide (FeNO)}

We used the NIOX MINO ${ }^{\circledR}$ device (Aerocrine Inc., Morrisville, NC) to measure the amount of nitric oxide in the air the participant breathed out. Nitric oxide is a gas produced by the airways, and elevated levels can be a sign of eosinophilic airway inflammation in asthma [Dweik et al. 2011]. In adults, fractional nitric oxide concentration in exhaled breath above 50 parts per billion (ppb) are considered elevated. In adults with asthma, elevated levels can indicate that their asthma is uncontrolled [Dweik et al. 2011]. 


\section{Impulse Oscillometry}

Many occupational lung diseases (e.g., COPD, asthma) involve the small airways; however, this part of the lung is difficult to evaluate noninvasively. Oscillometry is a helpful technology to understand the effects of occupational exposures on the small airways. There are no contraindications to the test as this test is conducted using regular breathing and does not require a forceful exhalation [Smith et al. 2005]. Spirometry can be normal despite respiratory symptoms or evidence of small airways disease on lung biopsy [Oppenheimer et al. 2007; King et al. 2011]; therefore, oscillometry results complement spirometry and can be used when spirometry is not possible because of a contraindication.

We used an impulse oscillometry machine (CareFusion Corp., San Diego, CA) to measure resistance $(\mathrm{R})$, the energy required to propagate the pressure wave through the airways, and reactance $(\mathrm{X})$, which reflects the viscoelastic properties of the respiratory system. The impulse oscillometry testing machine sends sound waves called pressure oscillations at different frequencies (e.g., 5 Hertz and 20 Hertz) into the airways to measure how airways respond to these small pressures. The test calculates 1$)$ the airway resistance at different frequencies including 5 Hertz (R5) and 20 Hertz (R20), and the difference between R5 and R20 (DR5-R20); 2) the reactance at different frequencies including 5 Hertz (X5); 3) resonance frequency which is the frequency where there is no airway reactance; and 4) the total reactance $(\mathrm{AX})$ at all frequencies between 5 Hertz and the resonance frequency. The predicted values for $\mathrm{R}$ and $\mathrm{X}$ were based on sex and age according to reference values recommended by the manufacturer [Vogel and Smidt 1994]. R5 was considered abnormal (elevated) if the measured value was equal to or greater than 140 percent of the predicted R5. X5 was considered abnormal (decreased) if the value of the predicted X 5 minus measured X5 was equal to or greater than 0.15 kilopascals per liter per second $(\mathrm{kPa} /(\mathrm{L} / \mathrm{s})$. DR5-R20 values greater than 30\% were considered abnormal and evidence of frequency dependence [Smith 2015]. We interpreted the test as normal if both the R5 and X5 were normal [Smith 2015]. We defined possible large (central) airways abnormality as a normal X5 and elevated R5 with no evidence of frequency dependence. We defined a possible small airways abnormality if there was evidence of frequency dependence or a decreased X5 with or without an elevated R5. We defined possible combined small (peripheral) and large (central airways) abnormality as a decreased X5 and elevated R5 with no evidence of frequency dependence.

In some of our analyses, we explored impulse oscillometry data comparing results with the upper limit of normal determined in previous populations studied following the attack on the World Trade Center [Friedman 2011]. The same parameters were assessed (R5, R20, R5-20, and $\mathrm{AX}$ ), using different units (centimeters of water per liter per second $(\mathrm{cm} \mathrm{H} 2 \mathrm{O} / \mathrm{L} / \mathrm{s}), 1 \mathrm{~cm}$ $\mathrm{H} 2 \mathrm{O}=0.0980665 \mathrm{kPA}$ ). $\mathrm{R} 5$ greater than $3.96 \mathrm{~cm} \mathrm{H} 2 \mathrm{O} / \mathrm{L} / \mathrm{s}$ was considered above the upper limit of normal and indicated total airways resistance. R20 greater than $3.20 \mathrm{~cm} \mathrm{H} 2 \mathrm{O} / \mathrm{L} / \mathrm{s}$ was considered above the upper limit of normal and indicated large airways resistance. R5-20 is referred to as the frequency dependence of resistance, and if greater than $0.76 \mathrm{~cm} \mathrm{H} 2 \mathrm{O} / \mathrm{L} / \mathrm{s}$ was considered above the upper limit of normal and indicated small airways resistance. AX greater than $3.6 \mathrm{~cm} \mathrm{H} 20 \mathrm{~cm} / \mathrm{L} / \mathrm{s}$ was considered above the upper limit of normal and indicated heterogeneity of small airways function. 


\section{Spirometry}

The purpose of the spirometry test was to determine a person's ability to move air out of their lungs. Test results were compared with expected normal values. The test included three measurements or calculations: 1) forced vital capacity (FVC), (the total amount of air the participant can forcefully blow out after taking a deep breath), 2) forced expiratory volume in one second (FEV1) (the amount of air the participant can blow out in the first second of exhaling), and 3) the ratio of FEV1 to FVC. We used American Thoracic Society criteria for acceptability and repeatability [Miller et al. 2005].

We used a volume spirometer (dry rolling seal spirometer) to measure exhaled air volume and flow rates. We used equations for predicted values and lower limits of normal derived from NHANES III data to define abnormal spirometry [Hankinson et al. 1999]. We defined obstruction as an FEV1/FVC ratio less than the lower limit of normal with FEV1 less than the lower limit of normal; restriction as a normal FEV1/FVC ratio with FVC less than the lower limit of normal; and mixed obstruction and restriction as having FEV1, FVC, and FEV1 /FVC ratio all less than the lower limit of normal. We used the FEV1 percent predicted to categorize such abnormalities as mild, moderate, moderately severe, severe, or very severe [Pellegrino et al. 2005].

\section{Complete Blood Count (CBC)}

We obtained venous blood samples for CBCs. This test measures several different components within the blood including total number of red blood cells (RBCs), hemoglobin (Hgb) concentration inside RBCs, total number of white blood cells (WBCs), total number of each of the five types of WBCs (neutrophils, lymphocytes, monocytes, eosinophils, and basophils), and total number of platelets using a flow cytometer. Normal eosinophil counts are defined by the laboratory as the range that includes $95 \%$ of healthy people of the same sex, age, and race. We considered an elevated eosinophil count combined with work-related respiratory symptoms indicated a possible case of work-related non-malignant respiratory disease [Bascom et al 1988, 1990].

\section{Statistical Analyses}

We calculated frequencies and standardized morbidity ratios (SMRs) and their associated 95\% confidence intervals (CI). The SMRs compared prevalences of symptoms and spirometric abnormalities among participants to expected prevalences of a sample of the general population reflected in the NHANES III (1988-1994, symptom and spirometry data), NHANES 2007-2012 (symptom data), and NHANES 2007- 2010 (spirometry data) adjusting for sex, race/ethnicity, age (less than 40 years old or 40 years or greater), and cigarette smoking categories (ever/never). For comparisons to the U.S. population, we used the most recent NHANES survey available for the specific comparisons. A SMR above 1 indicates the prevalence of the health problem or spirometric abnormality is more common among participants than expected. A SMR of 1 indicates that the health problem or spirometric abnormality is as common among participants as expected. A SMR below 1 indicates the prevalence of the health problem or spirometric abnormality is less common among participants than expected.

We performed Poisson regression models using a sandwich variance estimator to estimate 
prevalence ratios to investigate potential associations between work-related health symptoms and job type (mixing, finishing, or extrusion departments, and non-production departments). We investigated associations between lung function (\% predicted FEV1, \% predicted FVC, and FEV1/FVC ratio) and job type using linear regression models. Final models were adjusted for smoking status (ever vs. never) and age (as needed).

Job type was categorized into production and non-production departments. Production departments included extrusion, finishing or mixing, and non-production included participants who reported their current department as administrative, containment, indirect, maintenance, or shipping. We estimated prevalence ratios of respiratory symptoms in participants from mixing, finishing, or extrusion departments to those in participants from non-production departments. We used non-production workers as the reference group because these departments did not routinely perform hands-on tasks involving the ovens, microwaves, or coating sprays. We defined upper respiratory symptoms when participants reported one or more of the following symptoms on the questionnaire: 1) stuffy, itchy, or runny nose; 2) episodes of sneezing; 3) episodes of nosebleeds; 4) sinusitis or sinus problems; 5) burning throat. We defined lower respiratory symptoms when participants reported one or more of the following symptoms on the questionnaire: 1) cough attacks; 2) awoke with chest tightness; 3) awoke with shortness of breath; 4) chest wheezing or whistling; 5) asthma attack; 6) breathing trouble; 7) trouble with phlegm; 8) shortness of breath on level ground or walking up a slight hill in past 12 months. We defined work-related upper respiratory symptoms as symptoms that improved away from work or were aggravated by work through responses to two specific questions: "when you are away from this plant on days off or on vacation, is the symptom: better, same, or worse" and "is there anything at work that causes or aggravates the symptom". We defined work-related lower respiratory symptoms as symptoms that improved away from work.

Statistical analyses were conducted using SAS software version 9.4 (Cary, NC). We considered $\mathrm{p} \leq 0.05$ to be statistically significant.

\section{Qualitative Ventilation Assessment, March 2018}

We conducted a qualitative ventilation assessment focused mainly on the performance of all local exhaust ventilation (LEV) systems associated with rubber production. We used three different fog generators to assess the capture efficiency of each opening into a LEV system (capture point). We used the C Breeze Fog Visualization Instrument (Degree Control, Inc., Milford, NH) and the Chauvet Hurricane 100 Fog Machine (Chauvet DJ, Sunrise, FL) when large quantities of fog were desired. For smaller or tight openings, we used handheld Smoke Pencil Puffer Sticks (Zero Toys, Inc., Concord, NH). These fog generators allowed visualization of air movement into and around LEV systems. If the fog was captured quickly and directly by the capture point, it was rated as having total capture and provided a good indication of acceptable control design and performance. If a majority of the fog was captured, but some was allowed to escape, capture was considered marginal at that point. If the majority of the fog escaped capture, that capture point was considered to have poor capture. Fog testing was conducted at every LEV capture point (unless inaccessible) along all CV production lines, all SDM production lines, the off-line spray booths in various finishing areas, and the mixing facility. Whenever possible, we took physical measurements 
of the capture point opening and noted the size of the exhaust ductwork attached to the hood/opening. When a measurement followed the length of the line (e.g., from extrusion to finished product), the term "long" was used to describe it. Similarly, if the measurement was in the vertical direction, the descriptor "high" was used. If the measurement was perpendicular to the line (e.g., from the front of an oven to the back side), the term "wide" was generally used, although the appropriate term "deep" was used to describe the depth of spray booths.

To document the results of fog testing, we developed our own naming convention that was applied to each production line. We assigned individual LEV capture points a letter (e.g., A, B, C, etc.), and the letters continued, in alphabetical order, for each capture point on the line from the extruder(s) to the finished product end. Each lettered capture point was further described by the stack where it was exhausted out to the roof of the facility. Stacks were assigned for each line in numerical order (e.g., S1, S2, S3, etc.) from the extruder(s) to the finished product end. Often, multiple capture points on a given line were exhausted through the same stack. In some instances, capture points from one line were exhausted through a stack associated with another adjacent process line.

We also used the fog generators to describe the direction of air flow between the production area and adjacent non-production areas, break room, training room, and first aid room.

\section{Results}

\section{Initial Site Visit - January 2017}

\section{Informal Employee Interviews}

Of the 113 employees randomly selected for voluntary interviews, 94 were available the day of the interviews. Eighty-eight (94\%) participated in the interviews. Six employees were not interviewed because of language barriers, and no interpreters were available during the initial site visit. Sixteen (18\%) participants reported current respiratory symptoms that improved away from work. Another seven (8\%) participants reported their breathing was better away from work but did not list any current respiratory symptoms. Multiple employees reported their breathing was worse when they were near the D Building finishing area or extinguishing production area fires. Three employees reported they themselves or a coworker had changed job positions or departments because of breathing problems. Nine (10\%) participants reported concerns about the excessive heat in the production area during the summer months.

\section{Real-time Air Monitoring results}

Ten-second-average spot measurements of TVOCs in the morning of the second day were higher than 3,000 parts per billion (ppb) at certain sampling locations in extrusion line areas such as CV10, SDM EA, and SDM EF (Table 1). The highest mass concentration of total particulates in the 10 sampling locations was 6.5 milligram per cubic meter $\left(\mathrm{mg} / \mathrm{m}^{3}\right)$. The number of particulates measured in five of the 10 locations during the morning of the second day exceeded the upper limit of detection (500,000 particles per cubic centimeter) of the direct reading device. Concentrations of $\mathrm{CO}$ ranged from 0.9 parts per million (ppm) to 7.1 ppm. 


\section{Time-integrated Air Sampling of individual VOCs}

We observed that employees were exposed to mixture of chemicals. We detected more than 90 VOCs in the time-integrated air samples from the 10 locations using TD sampling tubes. Of the VOCs listed in the EPA TO-17 method, 12 VOCs were identified and quantified, but the rest of the VOCs were identified using a semi-quantitative method based on total ion chromatogram without standard materials. Of the 12 VOCs, 11 compounds had personal OELs established by NIOSH, OSHA, or the American Conference of Governmental Industrial Hygienists (ACGIH®). Area sample concentrations of these 11 VOCs in the 10 fixed locations were all below the applicable NIOSH, OSHA, or ACGIH OELs (Table 2). However, please note that NIOSH RELs, OSHA PELs, and ACGIH threshold limit values (TLVs) are intended to be directly compared to personal measurements in the breathing zone during the work shift. Area air samples can highlight areas with higher exposure risk.

The number of VOCs detected per sampling location ranged from 36-48. We detected at least 16 VOCs across all 10 locations, including 2-methyl pentane, 2-methyl propane, 2-propanol, 2-propanone, 2,3-dimethyl butane, 3-methyl hexane, 3-methyl pentane, benzene, carbon disulfide, ethylbenzene, heptane, methyl cyclohexane, naphthalene, styrene, toluene, and xylene (o-, m-, and p-). We detected at least 14 VOCs exclusively from the extrusion line areas near the mixing department, including 2-ethylacrolein, carbamic acid methyl ester, isothiocyanatocyclohexane, N-butyl-n-methyl-1-butanamine, N-ethyl-2propanamine, dodecamethylcyclohexasiloxane, dibutylcyanamine, methylester dodecanoic acid, formamide, N, N-dimethylmethanamine, phenol, difluorodimethyl silane, siloxane, and tetrachloroethylene. We detected at least 19 VOCs exclusively from another extrusion line areas near the finishing department, including 1,3,5-trimethylbenzene, 1-methyl2-pyrrolidinone, acetaldehyde, acid ester, bicycloheptene ethylidene isomer, methyl cyclopentane, dipropylene glycol methyl ether and its isomer, 2-(2-butoxyethoxy)-ethanol, 2-butoxyethanol, ethyl-2-cyano-trans-3-(1-naphthyl)-acrylate/siloxane, N,N-dimethyl formamide, formic acid, 2,3-dimethyl hexane, isopropylcyclobutane, N-methyl-N-nitrosomethanamine, $\mathrm{p}$ - or m-xylene, pyridine, sulfur dioxide, and trimethylamine. We detected at least five VOCs exclusively from the production area, including octane, 1,1,3-trimethyl cyclohexane, dimethyl cyclohexane/isomer, ethyl cyclohexane, and 2-methyl-2-propanamine. Safety data sheets provided by the company indicated that styrene and 3-methyl-pentane might be respiratory sensitizers, and some detected VOCs such as acetaldehyde, heptane, naphthalene, phenol, p-isopropyltoluene, pyridine, and tetrachloroethylene might be skin sensitizers.

\section{Medical Survey Results — June 2017}

\section{Demographics}

Of the 649 employees listed on the roster, 365 (56\%) participated in the medical survey. Interpreters were required for 139 participants, including Arabic (7\%, $n=26)$, Burmese (20\%, $n=72)$, Spanish $(10 \%, n=36)$, and Vietnamese $(1 \%, n=5)$. The majority of participants were male $(65 \%)$ and white $(51 \%)$, with a median age of 44 years and a median tenure at the company of 3.3 years; 150 (41\%) were current or former smokers (Table 3 ). 
One participant did not complete the questionnaire. Of the 364 participants who completed the questionnaire, $301(83 \%)$ reported spending more than five hours each shift in the production area (mixing, extrusion, or finishing departments). A department list, made from the employee roster, was provided during the questionnaire, and participants reported they worked in the following departments: administrative $(3 \%, n=12)$, containment $(1 \%, n=4)$, corporate $(5 \%, n=20)$, extrusion $(17 \%, n=63)$, finishing $(60 \%, n=217)$, indirect $(5 \%, n=19)$, maintenance $(2 \%, n=9)$, mixing $(3 \%, n=12)$, and shipping $(2 \%, n=8)$ (Table 3$)$. Fourteen participants (4\%) reported changing jobs, job duties, or work areas at this facility because of breathing problems. Ten (71\%) of the 14 participants who reported changing jobs, job duties, or work areas because of breathing problems worked in molding and finishing. Because extinguishing production area fires was reported as a source for breathing trouble during the informal interviews, a question was added to the questionnaire about participating in fire responses. Fifty-two (14\%) participants reported extinguishing fires in the past 12 months, with 34 out of $52(65 \%)$ reporting they participated in two or more fire responses.

\section{Symptoms and Self-Reported Diagnoses}

The prevalence of self-reported symptoms over the last 12 months at the time of the survey are listed in Table 4. Upper respiratory symptoms were the most commonly reported symptoms $(74 \%, n=269)$ (Table 4). Stuffy, itchy, or runny nose $(60 \%, n=218)$ was the most commonly reported upper respiratory symptom. Of the 269 participants who reported upper respiratory symptoms, 160 reported their symptoms improved when away from work. Eighty-five participants answered the question "is there anything at work that causes or aggravates these nose symptoms?" Of the 218 participants that reported stuffy, itchy, or runny nose symptoms, 85 reported their nasal symptoms were caused or aggravated by the spray coating applied during the molding and finishing process, smoke in the production area, smoke from the extrusion ovens, or smoke from the extrusion process.

Of the 52 participants who were involved in extinguishing fires, $42(81 \%)$ reported one or more upper respiratory symptoms, and 33 (63\%) had work-related symptoms. The most common work-related upper respiratory symptoms for participants involved in extinguishing fires included stuffy, itchy, or runny nose $(46 \%, n=24)$ and episodes of sneezing $(31 \%, n=16)$ (data not shown in Table).

Lower respiratory symptoms in the last 12 months were reported by 229 (63\%) participants (Table 4). Chest wheezing or whistling was the most commonly reported lower respiratory symptom $(26 \%, n=95)$ closely followed by shortness of breath on level ground or walking up a slight hill $(25 \%, \mathrm{n}=92)$ and trouble with phlegm $(25 \%, \mathrm{n}=92)$. Work-related lower respiratory symptoms were reported by 103 (28\%) participants. Breathing trouble was the most commonly reported work-related lower respiratory symptom $(13 \%, n=46)$ followed closely by trouble with phlegm $(12 \%, n=42)$ and usual cough $(11 \%, n=40)$.

When evaluating work-related symptoms by department, work-related symptoms (e.g., respiratory, eye, or skin) were generally higher in extrusion, finishing, and mixing departments than in non-production departments (Table 5). 
Sixty-one participants (17\%) reported a diagnosis of hay fever or nasal allergies, and eightyfour $(23 \%)$ reported sinusitis or sinus infection. Almost half of the employees were first diagnosed with hay fever/nasal allergies $(40 \%, n=24)$ or sinus infection $(54 \%, n=42)$ by a physician or healthcare provider after starting employment at the rubber manufacturing facility (Table 6).

Thirty-one participants $(8.5 \%)$ reported a diagnosis of asthma, $21(6 \%)$ reported chronic bronchitis, and five (1\%) reported COPD (Table 6). Of the 31 participants, who reported a diagnosis of asthma by a physician or healthcare provider, 25 had experienced one or more asthma symptoms in the previous 12 months, and nine were diagnosed after starting employment at the rubber manufacturing facility. All participants with COPD were diagnosed after beginning employment at the rubber manufacturing facility.

\section{Medical Tests}

Most (89\%) spirometry tests were normal; 25 (7\%) spirometry were interpreted as having a restrictive pattern, seven (2\%) an obstructive pattern, and two (1\%) a mixed pattern (Table 7). Of the 363 participants that completed IOS, 249 (69\%) were interpreted as normal; $63(17 \%)$ were interpreted as consistent with a small airways abnormality; 33 (9\%) were interpreted as consistent with large airways abnormality, and $18(5 \%)$ were interpreted as consistent with small and large airways abnormalities. Of the 347 participants that completed FENO, 15 (4\%) had elevated test results. Of the 31 participants who reported asthma, two had spirometry tests with an obstructive abnormality, and eight (25\%) had IOS interpreted as consistent with a small airways abnormality.

\section{Complete Blood Count}

Of the 352 participants who had their blood drawn, 29 had white blood cell count results interpreted as above the normal limits; 23 (7\%) participants had an absolute eosinophil count above the normal limits. Fourteen $(61 \%)$ of the 23 participants with elevated absolute eosinophil counts reported their current department as finishing (data not shown in Table).

\section{NHANES Comparison of Symptoms, Diagnoses, and Spirometry Results}

Compared with the U.S. general population, medical questionnaire survey participants were $2.5(95 \% \mathrm{CI}=2.1-3.1)$ times more likely to report wheeze and 1.5 times more likely to report shortness of breath on level ground (95\% CI=1.2-1.9) (Table 8). Participants were 1.3 (95\% $\mathrm{CI}=1.1-1.5)$ times more likely to report stuffy, itchy, or runny nose in the last 12 months compared with the U.S. general population.

Participants from extrusion, finishing, and non-production departments were 1.2 to 1.4 times more likely to report stuffy, itchy, or runny nose compared with the general population (Table 9). Participants who worked in the finishing department were 1.8 times more likely to report shortness of breath on level ground and 1.6 times more likely to report chronic bronchitis compared with the general population. Participants that worked in extrusion, finishing, or mixing were 1.8 to 3.7 times more likely to report wheeze in the last 12 months compared with the general population. Employees involved in extinguishing fires were 3.0 times more likely to report wheeze in the last 12 months compared with the U.S. general population 
(data not shown in table). In addition, there was not an excess of obstructive spirometry abnormalities in comparison to the general U.S. population, adjusted for age distribution, race/ethnicity, sex, and smoking history (Table 10).

Results of Multiple Regression Models of Symptoms and Lung Function Test Results by Production and Non-production Departments

Participants who reported working in extrusion had a significantly higher prevalence of work-related breathing trouble $(\mathrm{PR}=3.7,95 \% \mathrm{CI}=1.5-9.4)$ and one or more work-related upper respiratory symptoms $(1.8,95 \% \mathrm{CI}=1.0-3.0)$ compared with those in non-production departments (Table 11). Participants who reported working in mixing had a significantly higher prevalence of one or more work-related upper respiratory symptoms $(2.8,95 \% \mathrm{CI}=$ 1.3-6.0), work-related skin symptoms $(7.4,95 \% \mathrm{CI}=2.3-24.2)$, trouble with phlegm (4.1, $95 \% \mathrm{CI}=1.1-14.6)$, and usual cough $(4.3,95 \% \mathrm{CI}=1.2-15.2)$ compared with those in nonproduction departments. Participants who reported working in finishing had a significantly higher prevalence of work-related sinusitis or sinus problems $(2.8,95 \% \mathrm{CI}=1.0-27.9)$ compared with those in non-production departments.

The mean medical test parameters for spirometry, IOS, and FENO were normal for all departments (Table 12). The mean percent predicted FEV1, mean FEV1/FVC ratio, and mean airway resistance at $5 \mathrm{~Hz}$ were significantly lower $(-0.6,95 \% \mathrm{CI}=-1.0--0.1)$ for participants who worked in extrusion compared with participants in a non-production department. Participants that worked in finishing had a significantly higher mean FEV1/FVC ratio $(2.6,95 \% \mathrm{CI}=0.6-4.3)$ and lower mean FENO (-5.5, 95\% CI=-9.6 - -1.4) compared with those in non-production (Table 12). Eight participants who reported working in the shipping department had a mean percent predicted FEV1 (84.7) and mean FEV1/FVC (74.9) significantly lower than the mean percent predicted FEV1 (98.9) and FEV1/FVC (81.0) for all other departments (data not shown in table).

\section{Ventilation Assessment Results - March 2018}

Fog testing was conducted at every LEV capture point (unless inaccessible) along all CV and SDM production lines, the off-line spray booths in various finishing areas, and the mixing facility. The results from the qualitative fog testing are highlighted in Tables 13-17. With the exception of canopy hoods, most of the LEV systems throughout the plant, including all spray booths, provided good capture of released contaminants.

Other observations from the ventilation assessment were:

1. At times, the CV or SDM production lines were operated with the oven doors open, which have a negative effect on the associated LEV systems.

2. The vertical distance between the rubber production lines and canopy hood openings on all respective production lines seemed excessive, which resulted in poor capture of contaminates at those locations.

3. Individual slot vents associated with the CV ovens were often caked with debris, which could impact the efficiency of LEV systems. 
4. Under certain conditions, when outside air was being supplied to the facility, significant cross-drafts were created that significantly impacted the effectiveness of LEV systems. This was particularly noticeable throughout the middle CV lines.

5. There were no LEV labels visible inside the production facility. The rooftop ventilation equipment was often labeled incorrectly.

6. Many of the exhaust stacks on the roof were at nearly the same height as air intakes that bring outdoor air into the facility, increasing the likelihood of re-entrainment of contaminated air into air intakes under certain outdoor environmental conditions.

7. At the time of testing, the production area was appropriately negative to all key adjacent non-production spaces (Table 14). This means that air was flowing from the cleaner, non-production spaces into the production spaces.

\section{Discussion}

Rubber manufacturing uses hundreds of different types of chemicals depending on the desired final product. During the rubber manufacturing process, many different dusts, gases, vapors, mists, fumes, and chemical byproducts are produced [McMichael et al. 1976; Jonsson et al. 2008; IARC 2012]. Rubber manufacturing emissions contain known respiratory irritants and sensitizers that can lead to long-term respiratory problems [Governa et al. 1987; Zuskin et al.1996; Akca et al. 2011]. For other rubber manufacturing emission components, the respiratory exposure effects are unknown. Many of the known and unknown respiratory hazards found in rubber manufacturing emissions do not have established occupational exposure limits.

\section{Industrial hygiene survey}

Although we cannot directly compare our time-integrated area measurements of VOCs at a fixed location to OELs for personal exposure during the work shift, 11 individual VOC concentrations with available OELs, that were quantified from the VOC list of EPA TO-17 method, were all much lower than the OSHA PELs, NIOSH RELs, or ACGIH TLVs (lower than $0.05 \%$ of the lowest OEL). We detected more than 90 VOCs in air from our survey; however, no OELs exist for 67 of the VOCs detected in the survey.

We found that the number of submicron particulates measured in real time exceeded the upper limit of detection (500,000 particles per cubic centimeter) of the direct reading device in five of the 10 locations. The EPA reported in a draft document for public review that shortterm exposure to ultrafine particles (aerodynamic diameter $<0.1 \mu \mathrm{m}$ ) likely causes nervous system effects, and there is also suggestive evidence that short- and long-term exposures to ultrafine particles are causally associated with cardiovascular, respiratory, nervous system, and metabolic effects [EPA 2018]. However, there is currently no OELs for submicron particulate matters.

A review of safety data sheets provided by the company and published scientific literature indicates that styrene and 3-methyl-pentane might be respiratory sensitizers and that 
some of the VOCs such as acetaldehyde, 5-ethyledene-bicyclo[2,2,1]hept-2-ene, N,Ndibutylformamide, heptane, naphthalene, phenol, p-isopropyltoluene, pyridine, and tetrachloroethylene might be skin sensitizers [Zeliger 2011]. In addition, many of the detected VOCs are respiratory irritants.

Each of the 10 samples collected from mixing, extrusion, and finishing departments detected at least 36 different VOCs, indicating mixed exposures of employees to those chemicals along with emission particles and fumes. In a situation of mixed exposure, the mixture can alter the expected health effects of individual respiratory irritants and sensitizers [Schwartz et al. 1996; Penn et al. 2005]. Previous studies have also indicated mixed exposures might increase the likelihood of non-malignant respiratory disease [Schwartz and Dockery 1996; Penn et al. 2005]. Therefore, there is always a possibility of synergistic, potentiated, or additive effects among the multiple chemicals in the exposed workers [Alessio 1996; Zeliger 2003]. This indicated, that although past exposures to individual VOCs are well below the OEL and individuals might have little to no known respiratory health effects, simultaneous or sequential exposure to multiple contaminants of VOCs, particles, and fumes might produce adverse health effects through these toxicodynamic interactions. Thus, it is important to minimize employee exposure to rubber manufacturing emissions through engineering controls such as maintaining a good ventilation system.

\section{Medical survey}

From our medical survey and subsequent data analyses, we found that 1) compared with the U.S. general population, there was an excess in lower respiratory symptoms (wheeze and shortness of breath on level ground) and nose symptoms (stuffy, itchy, or runny nose) in survey participants; 2) the excess of those symptoms was found in participants from all three production departments and non-production departments; 3) 59\% of participants who reported one or more upper respiratory symptoms and $45 \%$ of those who reported one or more of lower respiratory symptoms also reported their symptoms improved when away from work, indicating a potential association between their symptoms and the workplace environment; and 4) compared with those from non-production departments participants from mixing and extrusion departments reported significantly higher prevalence of one or more work-related upper respiratory symptoms, those from extrusion department reported significantly higher prevalence of work-related breathing trouble, and those from finishing and mixing departments reported significantly higher work-related sinusitis/sinus problems. Although we cannot conclude the excess of respiratory symptoms among the participants of the medical survey from this rubber manufacturing facility is causally-related to an occupational exposure, the results from our medical survey were consistent to those from previous studies at other rubber manufacturing facilities [Thapa et al. 2019]; thus, indicating rubber manufacturing might be associated with respiratory symptoms and non-malignant respiratory disease.

Over $80 \%$ of the medical survey participants reported spending more than five hours a day in the production area of this rubber manufacturing facility. Previous studies have reported rubber manufacturing workers are at risk for acute and chronic respiratory symptoms because of exposure to the suspended particles, fumes, and VOCs [doPico et al. 1975; Fine and Peters 1976a; Fine and Peters 1976b; Fine and Peters 1976c; Fine et al. 1976; Gamble et al.1976; 
Korn el al 1978; Weeks et al. 1981a; Weeks et al. 1981b; Bascom et al. 1988; Tarlo 1992; Zuskin et al 1996; Kato and Leki 2005; Neghab et al. 2007; Akca et al 2011; Neghab et al. 2011; Attarchi et al. 2013]. A prospective cohort study by Lednar et al. followed a cohort of actively employed rubber workers over 10 years and reported a higher rate of pulmonary disability among workers in extrusion and curing process work areas compared with a control group [Lednar et al 1977]. Furthermore, a rubber manufacturing study by Attarchi et al., which reported significantly higher prevalence of respiratory symptoms among production workers compared with non-production workers, reported the highest concentrations of respirable dust in the extrusion and curing areas of the facility [Attarchi et al. 2013]. Rubber manufacturing emission exposure varies based on the type of rubber being produced; however, regardless of the type, rubber manufacturing workers can be exposed to mixture of numerous respiratory irritants in the form of gases, particles, and fumes [Akca et al. 2011].

In 2019, NIOSH investigators published a systematic review and meta-analysis of nonmalignant respiratory disease among workers in rubber manufacturing. This study identified 11 case reports of respiratory conditions, 30 cross-sectional studies, and 26 mortality studies [Thapa et al. 2019]. All 30 of the cross-sectional studies had evidence of an association between exposure to rubber manufacturing emissions and respiratory symptoms with 15 of the cross-sectional studies having a statistically significant higher prevalence of respiratory symptoms compared with controls [Fine and Peters 1976a; Fine and Peters 1976b; Fine and Peters 1976c; Fine et al. 1976; Gamble et al.1976a; Gamble et al.1976b; Weeks et al. 1981a; Weeks et al. 1981b; Bascom et al. 1988; Tarlo 1992; Zuskin et al 1996; Jonsson et al. 2007; Neghab et al. 2007; Jonsson et al. 2008b; Jonsson et al. 2009; Neghab et al. 2011; Attarchi et al. 2013]. Similar to our medical survey, respiratory symptoms reported among these crosssectional studies included nasal congestion, shortness of breath, cough, sputum production, trouble breathing, wheeze, chest tightness, and chest irritation. Additionally, 10 crosssectional occupational studies of exposure to rubber manufacture emissions have identified higher prevalences of non-malignant respiratory disease including sinusitis, pharyngitis, chronic bronchitis, emphysema, COPD, and asthma [Fine and Peters 1976a; Fine and Peters 1976b; Fine and Peters 1976c; Fine et al. 1976; Gamble et al.1976a; Lednar et al. 1977; Sparks et al. 1982; Thomas et al. 1986; Alexandersson et al. 1989; Zuskin et al. 1996; Meijer et al. 1998; Hnizdo et al. 2002].

Participants of the medical survey conducted at this facility were 2.5 times more likely to report wheezing or whistling in their chest in the last 12 months compared with the U.S. general population. Among the 30 cross-sectional studies identified in the NIOSH systematic review, 14 (47\%) reported an association with wheeze or whistling in the chest and exposure to rubber manufacturing emissions [Thapa et al. 2019]. Although there is a wide variation among rubber manufacturing processes, participants in these studies commonly reported working in the vulcanizing area, molding, thermoinjection process, curing process, and mixing [Fine and Peters 1976a-c; Bascom et al. 1988; Meijer et al. 1998; Jonsson et al 2007; Jonsson et al. 2009; Jonsson et al. 2009; Neghab et al 2011; Attarchi. et al 2013].

We found the prevalence of upper respiratory symptoms was generally higher than the prevalence of lower respiratory symptoms in those who participated in the medical survey. Over $40 \%$ of the medical survey participants reported one or more work-related upper 
respiratory symptom. In addition, in all three production departments prevalence of workrelated nose or eye symptoms, or sinusitis/sinus problems were significantly higher than in non-production workers. Although lower respiratory symptoms are more commonly associated with non-malignant respiratory disease, upper respiratory symptoms sometimes precede lower respiratory symptoms and the diagnosis of non-malignant respiratory disease such as asthma [Shaaban et al. 2008; EAACI Task Force on Occupational Rhinitis et al. 2008; Park et al. 2012; Rondón et al. 2012; Sahay et al. 2016]. Previous studies have indicated the risk of asthma is greater in individuals with chronic upper respiratory symptoms [Huoviene et al. 1999; Guerra et al. 2002; Fox and Lockey 2003; Koh and Kim 2003; Togias 2003; Volcheck 2004; Krouse et al. 2007]. Therefore, considering that upper respiratory symptoms can potentially progress to lower respiratory illnesses and the employees of this facility had significantly increased prevalence of upper respiratory symptoms with work-related patterns in more than half of them, over time employees at this facility might experience an increase in lower respiratory symptoms. A medical monitoring program might help identify early signs of lower respiratory symptoms and lower respiratory disease including asthma and COPD.

We found that employees who participated in fire extinguishing had a higher prevalence of work-related upper respiratory symptoms compared with employees who did not participate in extinguishing fires. Furthermore, employees who participated in fire responses reported exposure to high levels of smoke while extinguishing the fires. Firefighter occupational studies have indicated exposure to particulates including smoke and fumes is associated with increased rates of non-malignant respiratory disease [Kim et al. 2012; Schermer et al. 2014]. Smoke exposure levels combined with prevalence of work-related respiratory symptoms indicate employees who respond to facility fires might have a higher risk for developing non-malignant respiratory disease and respiratory protection should be considered to protect employees who respond to production area fires.

Five medical survey participants reported being diagnosed with COPD since starting employment at the rubber manufacturing facility. Although smoking and genetics are commonly recognized risk factors for COPD, previous studies have identified occupational and environmental exposures as commonly under-recognized risk factors [Lange et al. 1989; Lindberg et al. 2005; Fishwick et al. 2013; Halldin et al. 2015]. Furthermore, 15 to 19 percent of all COPD cases are caused by occupational exposures [Balmes et al. 2003; Blanc and Toren 2007; Toren and Blanc 2009; Bang et al. 2013; Vestbo et al 2013]. Research has indicated occupational environments with inhalation exposure to dusts, fumes, and gases might increase the risk for COPD [Vestbo et al 2013]. Additionally, rubber manufacturing was identified as one of the industries associated with a high prevalence of COPD [Fine and Peters 1976a; Lednar et al. 1997; Korn et al. 1978; Hnizdo et al 2002]. Although all five COPD cases were diagnosed in employees after they began working at the facility, because of the complexity of rubber manufacturing emission exposures and the limits of the type of data we collected, we were not able conclude any of the COPD cases were work-related.

The respiratory symptoms and breathing test abnormalities observed in the medical survey participants are not specific to a particular respiratory problem or disease. Although the prevalence of some symptoms was greater than in the general population, we cannot prove 
causal association between workplace exposure and respiratory symptoms. Additionally, the median tenure for employees who participated in the medical survey was 3.3 years. This short tenure might indicate a healthy worker effect, which describes a phenomenon where employees tend to be healthier than the general public, because employees who are ill leave the workforce or move to a different job if their current job causes severe health symptoms. The healthy worker effect might explain why there was not a significant difference in lung function tests compared with the general population, and better lung function tests results among production (extrusion and finishing) employees compared with non-production employees. Working in rubber manufacturing can be a physically demanding job for most production (extrusions, finishing, and mixing) employees; employees with decreased lung function can move to less physically demanding jobs or to another industry entirely because of difficulty breathing.

\section{Ventilation}

With the exception of the canopy hoods, the LEV systems throughout the plant provided good capture of released contaminants. The marginal to poor performance of the canopy hoods was attributable to the hood height related to the rubber production lines (i.e., source of emissions) moving under the hood. Shortening the vertical distance between the rubber and the hood opening or adding a curtain might improve the canopy hoods performance. During our assessment, we noted the LEV systems associated with the ovens worked best when the oven doors were closed. Additionally, we noted significant cross-drafts when outside air was supplied to the facility under certain conditions. The cross-drafts altered the effectiveness of the LEV systems, especially in the middle CV lines. These cross-drafts reinforce the importance of keeping the oven doors closed as much as possible while the $\mathrm{CV}$ lines are running.

Air flows between two spaces from the area of higher pressure (or "positive" pressure) to the area of lower pressure (or "negative" pressure). Using fog allowed us to visualize the direction of the air flow around doors between these adjacent spaces and visually determine the pressure relationship between them. Generally, the production area would be expected to have the highest concentrations of airborne contaminants. To keep these contaminants confined to the production area and prevent them from spreading into adjacent areas, the production area should be maintained under negative pressure relative to the adjacent spaces (or the adjacent spaces should be maintained under positive pressure relative to the production area). This would ensure that air from the adjacent spaces flows into the production area. Our results demonstrated that the production area was appropriately negative to all key adjacent spaces, at least under the conditions of our testing. While these are the desired results, it should be noted that any changes in ventilation system operation in either area (e.g., supplying more outdoor air to production, an air-handling unit in the break room cycling off, etc.) or propping doors open could easily affect the pressure relationships, resulting in air flowing in the wrong direction. Doors between the production spaces and all adjacent areas should be kept closed whenever possible.

\section{Hot Work Environments}

During our voluntary, confidential interviews with employees in January 2017, some participants reported concerns about the excessive heat in the production area during the summer months. During that same visit, management reported passing out popsicles to 
employees during summer months to help with the heat in the production areas. During this health hazard evaluation, we did not evaluate heat in the facility during the summer months. However, in general, workers who work in hot environments, such as fire fighters, bakery workers, farmers, construction workers, surface miners, boiler room workers, factory workers, and others, can be at risk for heat stress [NIOSH 2016, 2018]. Exposure to extreme heat can result in occupational injuries and illness including death. The NIOSH document, Criteria for a Recommended Standard: Occupational Exposure to Hot Environments [NIOSH 2016] has helpful information on keeping workers safe in hot work environments, including information on personal protective equipment and clothing that can be used to control heat stress. NIOSH also has a webpage (https://www.cdc.gov/niosh/topics/heatstress/default.html) on heat stress with links to additional resources [NIOSH 2018].

\section{Limitations}

This health hazard evaluation was subject to limitations. First, because of the complexity of rubber manufacturing emissions, we did not perform a comprehensive exposure assessment for individual workers. Therefore, our epidemiologic analyses were limited to using work department information as a surrogate measure for exposure, which might have created random misclassification in actual exposure. This nondifferential misclassification, if present, tends to underestimate true associations between exposures and health outcomes. Second, the health data collected was self-reported information from employees who volunteered to participate in the medical survey, possibly subjecting our epidemiologic analyses to information bias. One of the most common types of information bias is recall bias where participants are more likely to report an exposure or symptom. However, the upper respiratory symptom results of our medical survey are similar to the respiratory symptoms reported in previous rubber manufacturing worker studies [Thapa et al. 2019].

\section{Conclusions}

None of the area sample VOC measurements identified and quantified, with EPA TO-17 method during the walkthrough survey, were above available OELs for personal exposures. However, we cannot directly compare our area air sample measurements at fixed locations to OELs for personal exposures measured in workers' breathing zones during their work shifts. However, simultaneous or sequential exposures to multiple VOCs, particles, and fumes in the workplace might produce adverse health effects in exposed employees through the toxicodynamic mechanisms of synergistic, potentiated, or additive effects. A higher prevalence of upper and lower respiratory symptoms compared with the U.S. general population were reported among production and non-production employees who participated in the medical survey. More than $40 \%$ of the symptomatic employees reported that their symptoms were caused or aggravated by work-related processes including the spray coating applied during the molding and finishing process, smoke in the production area, smoke from the extrusion ovens, or smoke from the extrusion process. All these findings might indicate there is an excess of respiratory symptoms in employees of the facility, which might be associated with workplace environments, especially production departments although we were not able to prove the causal associations. It will be important to maintain good ventilation systems and implement a medical monitoring program to identify early signs of non-malignant respiratory disease including asthma and COPD. 


\section{Recommendations}

On the basis of our findings, we recommend the actions listed below. Our recommendations are based on an approach known as the hierarchy of controls. This approach groups actions by their likely effectiveness in reducing or removing hazards. In most cases, the preferred approach is to eliminate hazardous materials or processes and install engineering controls to reduce exposure or shield employees. Until such controls are in place, or if they are not effective or feasible, administrative measures and personal protective equipment might be needed.

\section{Engineering Controls}

Engineering controls reduce employees' exposures by removing the hazard from the process or by placing a barrier between the hazard and the employee. Engineering controls protect employees effectively without placing primary responsibility of implementation on the employee.

1. Operate the CV or SDM production lines with the oven doors closed to improve the effectiveness of the associated LEV systems.

2. Shorten the vertical distance between the rubber production lines and canopy hood openings on all respective production lines. If that is impractical, consider adding curtains to extend the effective range of the canopy hoods to achieve better capture of airborne contaminants at those locations.

3. Keep slot vents associated with the CV ovens cleaned, particularly during quarterly preventive maintenance cycles, to maintain efficiency of LEV systems.

4. When future modifications are made to outdoor air delivery systems, ensure the air supplied to the factory space is diffused in a manner to minimize cross-drafts that alter the effectiveness of the LEV systems.

5. Label exhaust points inside the facility and on the roof accurately to make identifying and troubleshooting potential problems easier.

6. Consider raising roof stack heights during ventilation system renovations to reduce the potential for re-entrainment of contaminated air back into the production space.

7. As it was during the ventilation assessment, maintain the production area under negative pressure relative to adjacent nonproduction spaces (including the break room) at all times. This will minimize the potential for airborne contaminants generated in the production space to flow to other adjacent spaces where employees can spend significant amounts of time. Doors between the production areas and adjacent spaces should be kept closed at all times. This negative pressure relationship should be maintained during and after all planned ventilation system renovations.

\section{Administrative Controls}

Administrative controls are employer-dictated work practices and policies implemented to reduce or prevent hazardous exposures. Their effectiveness depends on employer commitment and employee acceptance. Regular monitoring and reinforcement are necessary 
to ensure that policies and procedures are followed consistently.

1. Ensure employees understand potential health effects of exposures (e.g., carbon black, rubber manufacturing emissions, VOCs, $\mathrm{CO}, \mathrm{CO} 2$, heat stress) in the workplace and how to protect themselves. OSHA's Hazard Communication Standard, also known as the "Right to Know Law" [29 CFR 1910.1200], requires that employees are informed and trained on potential work hazards and associated safe practices, procedures, and protective measures.

2. Ensure employees are educated to consider the risks of further exposure if they develop respiratory symptoms (e.g., cough, shortness of breath, wheezing) that are progressive and severe in degree. Employees should report new, persistent, or worsening symptoms to their personal healthcare providers and to a designated individual at this workplace. Employees with new, persistent, or worsening symptoms should also share this report with their healthcare providers.

3. Ensure all employees have and understand the health and safety communication materials. Among the medical survey participants, 38\% spoke and read Arabic, Burmese, or Spanish, and requested or needed an interpreter to participate. Use infographics or translate health and safety information into common languages spoken at the facility.

\section{Personal Protective Equipment}

Personal protective equipment in the form of respiratory protection is considered the least effective means for controlling hazardous respiratory exposures because breakdowns in implementation can result in insufficient protection. Proper use of respiratory protection (respirators) requires a comprehensive respiratory protection program and a high level of employee and management involvement and commitment to assure that the right type of respirator is chosen for each hazard, respirators fit users and are maintained in good working order, and respirators are worn when they are needed. Supporting programs such as training, change-out schedules, and medical assessment might be necessary. Respirators should not be the sole method for controlling hazardous inhalation exposures. Rather, respirators should be used until effective engineering and administrative controls are in place.

1. Respiratory protection is a potential option to further reduce exposures to smoke and rubber manufacturing emissions for employees. Because participants who reported responding to production area fires had a higher prevalence of work-related upper respiratory symptoms compared with participants who did not assist with extinguishing fires, respiratory protection should be considered for employees who participate in extinguishing fires. If respiratory protection is used, NIOSH-certified respirators should be fitted with organic vapor cartridges and particulate filters. The choice of respirator should be guided by a personal exposure sampling for rubber manufacturing emissions [NIOSH 2004]. Respirators have assigned protection factors (APF). APF refers to the highest level of protection a properly selected respirator can provide. For instance, airpurifying half-face respirators have an APF of 10, and air-purifying full-face respirators have an APF of 50. Also, there are powered-air purifying respirators that have APFs of 25,50 , or 1000 . The OSHA APFs can be found in Table 1 of OSHA Respiratory 
Protection Standard at https://www.osha.gov/pls/oshaweb/owadisp.show_document?p $\underline{\mathrm{id}}=12716 \& \mathrm{p}$ table $=$ STANDARDS.

If mandatory respiratory protection is used, a written respiratory protection program is required by the OSHA Respiratory Protection Standard (CFR 29 1910.134), or the equivalent state standard in states with Federal OSHA-approved State Occupational Safety and Health plans.

\section{Medical Monitoring}

The purpose of a medical monitoring program is to help assure the health of employees who have workplace exposures (e.g., rubber manufacturing emissions) known to pose risk for potentially serious health conditions such as asthma or COPD.

1. Institute a medical monitoring program for employees who work or assist in the production area (extrusion, finishing, or mixing). The medical monitoring program should consist of evaluation with a questionnaire (to obtain health and work task information) and spirometry (to assess lung function) at baseline to establish employees' baseline in lung function followed by annually to monitor for respiratory symptoms and any abnormal decline in lung function. Subsequently, an annual questionnaire evaluation should occur to monitor for respiratory symptoms. New or worsening respiratory symptoms should prompt additional medical evaluation including spirometry.

\section{Smoking Cessation Program}

In a workplace with risk of occupational lung disease, prevention of smoking-related lung disease is important and makes the detection of work-related adverse effects easier. We recommend implementing a smoking cessation program to assist employees to stop smoking. The Centers for Disease Control and Prevention offers tools and resources for setting up a smoking cessation program [CDC 2018b]. 


\section{Appendix A: Tables}

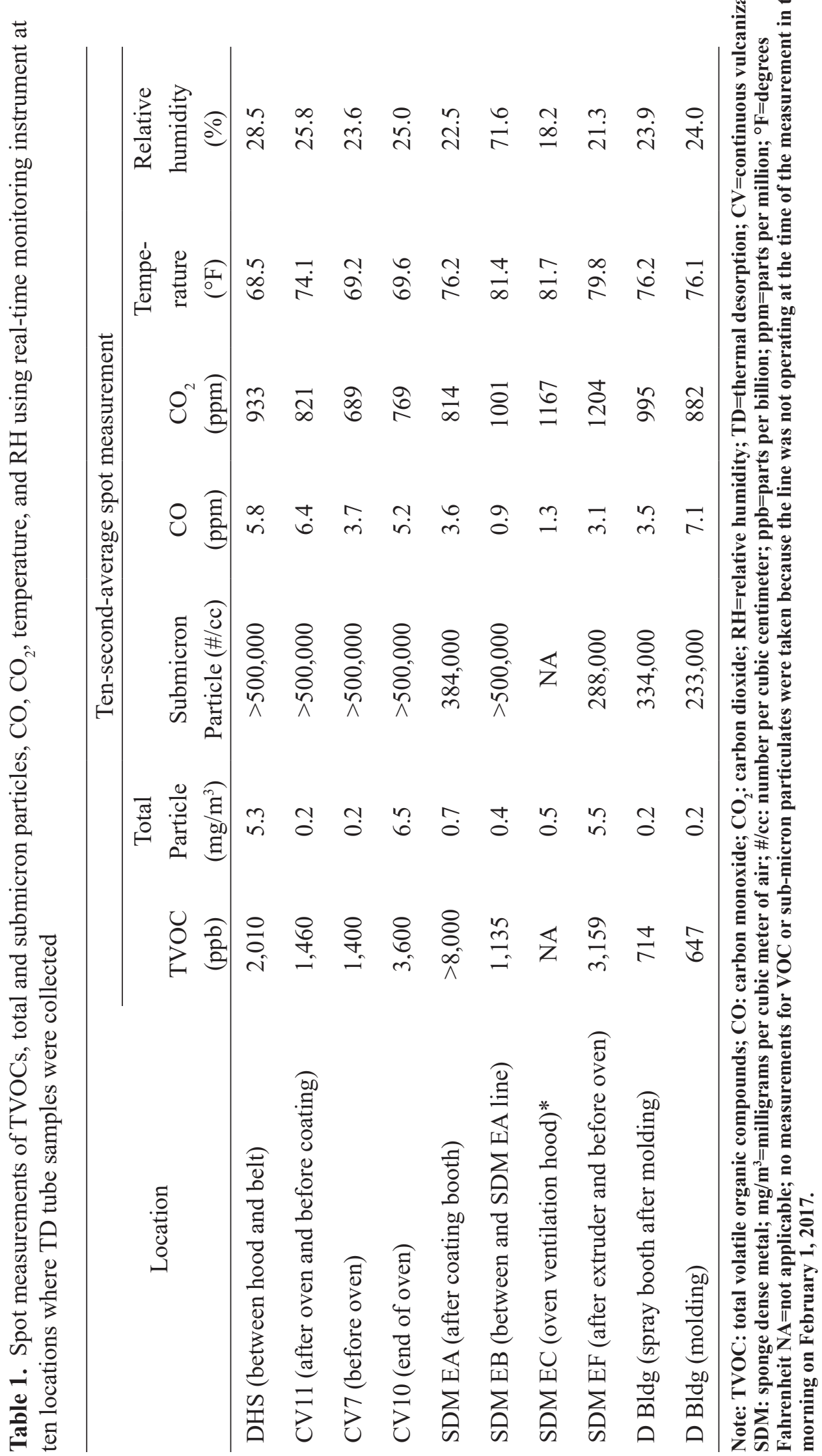




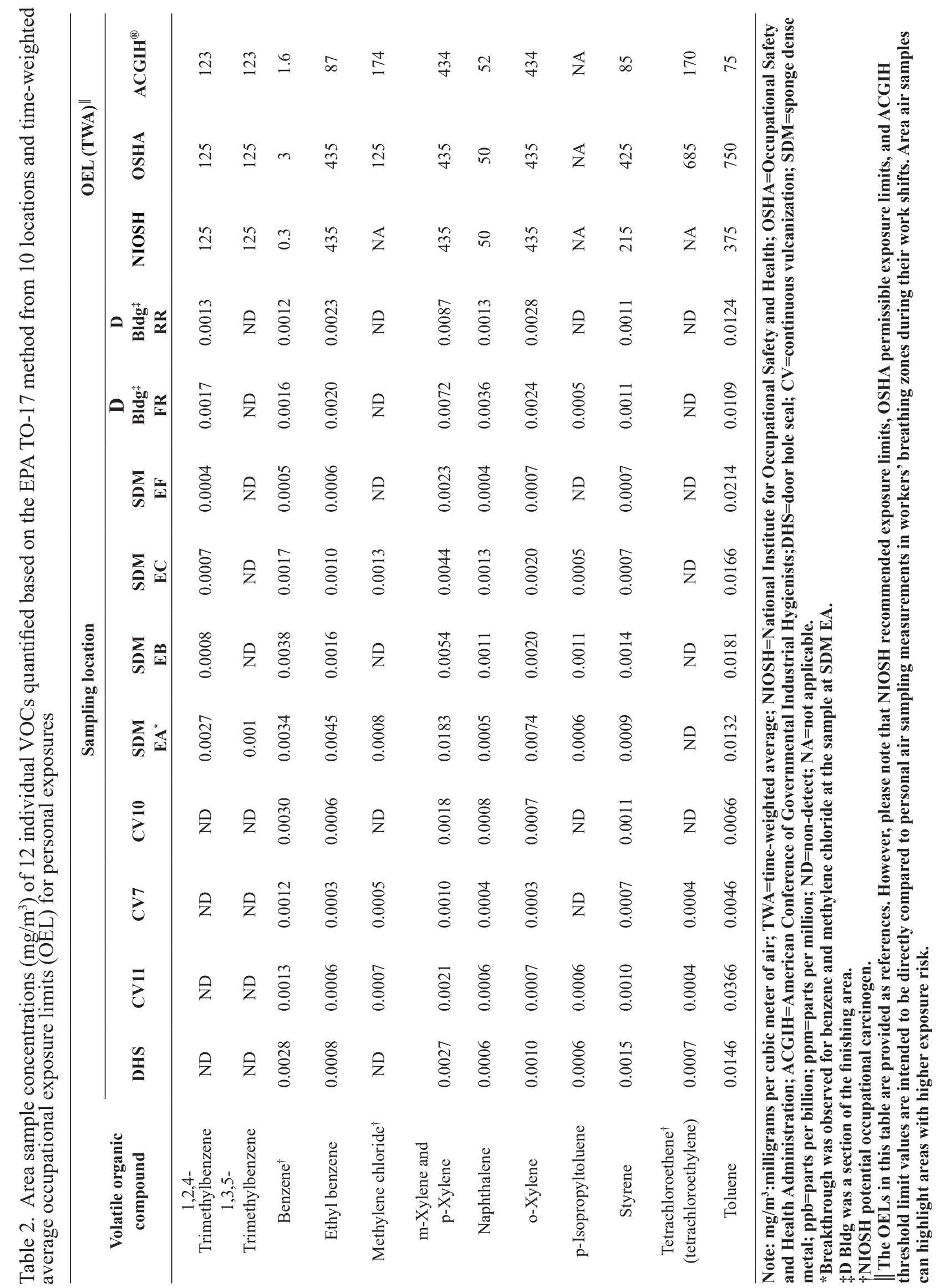


Table 3. Characteristics of participants ( $n=364 *)$, NIOSH medical survey, July 2017

\begin{tabular}{|c|c|}
\hline & No. $(\%)$ \\
\hline \multicolumn{2}{|l|}{$\underline{\text { Sex }}$} \\
\hline Male & $235(65)$ \\
\hline Female & $129(35)$ \\
\hline \multicolumn{2}{|l|}{ Questionnaire language } \\
\hline English & $225(62)$ \\
\hline Burmese & $72(20)$ \\
\hline Spanish & $36(10)$ \\
\hline Arabic & $26(7)$ \\
\hline Vietnamese & $5(1)$ \\
\hline \multicolumn{2}{|l|}{ Department } \\
\hline Administrative & $12(3)$ \\
\hline Containment & $4(1)$ \\
\hline Corporate & $20(5)$ \\
\hline Extrusion & $63(17)$ \\
\hline Finishing & $217(60)$ \\
\hline Indirect & $19(5)$ \\
\hline Maintenance & $9(2)$ \\
\hline Mixing & $12(3)$ \\
\hline Shipping & $8(2)$ \\
\hline \multicolumn{2}{|l|}{$\underline{\text { Smoking status }}$} \\
\hline Never & $214(59)$ \\
\hline Former & $71(20)$ \\
\hline Current & $79(22)$ \\
\hline Median age (years) & 43 (Range: 19-68) \\
\hline Median tenure (years) & 3 (Range: $0.1-32$ ) \\
\hline
\end{tabular}

Note: NIOSH=National Institute for Occupational Safety and Health.

*Number of employees who completed the questionnaire.

†Workers who answered "yes" to the question "have you ever been told by a physician or other healthcare provider that you have asthma?" 
Table 4. Prevalence of reported symptoms, NIOSH medical survey, June 2017 (N=364*)

\begin{tabular}{|c|c|c|}
\hline Symptom & $\begin{array}{l}\text { Overall } \\
\text { Number }(\%)\end{array}$ & $\begin{array}{c}\text { Work-related } \\
\text { Number }(\%)\end{array}$ \\
\hline Stuffy, itchy, or runny nose & $218(60)$ & $85(23)$ \\
\hline Sneezing episodes & $157(43)$ & $67(18)$ \\
\hline Nose bleeds & $50(14)$ & $22(6)$ \\
\hline Nose symptoms ${ }^{\dagger}$ & $252(69)$ & $147(40)$ \\
\hline Sinusitis or sinus problems & $100(27)$ & $30(8)$ \\
\hline Burning throat & $59(16)$ & $28(8)$ \\
\hline Upper respiratory symptoms ${ }^{* *}$ & $269(74)$ & $160(44)$ \\
\hline Chest wheezing or whistling & $95(26)$ & $38(10)$ \\
\hline $\begin{array}{l}\text { SOB on level ground or } \\
\text { walking up a slight hill }\end{array}$ & $92(25)$ & - \\
\hline Breathing trouble & $84(23)$ & $46(13)$ \\
\hline Awoke with chest tightness & $53(15)$ & $31(9)$ \\
\hline Awoke with SOB & $43(12)$ & $21(6)$ \\
\hline Usual cough & $85(23)$ & $40(11)$ \\
\hline Cough attacks & $82(23)$ & $36(10)$ \\
\hline Trouble with phlegm & $92(25)$ & $42(12)$ \\
\hline Asthma attack & $20(5)$ & $8(2)$ \\
\hline Lower respiratory symptoms ${ }^{\dagger \dagger}$ & $229(63)$ & $103(28)$ \\
\hline Eye symptoms" & $141(39)$ & $66(18)$ \\
\hline Skin symptoms & $60(16)$ & $28(8)$ \\
\hline
\end{tabular}

Note: NIOSH=National Institute for Occupational Safety and Health; N=Number of participants; SOB=shortness of breath

Work-related="better" response to "when you are away from this plant on days off or on vacation, is the symptom better, same or worse, or "yes" response to "Is there anything at work that causes or aggravates the symptom". *Number of employees who completed the questionnaire.

$\uparrow$ Nose symptoms include one or more of the following: 1) stuffy, itchy, or runny nose, 2) episodes of sneezing, or 3) episodes of nose bleeds.

**Upper respiratory symptoms include one or more of the following: 1) stuffy, itchy, or runny nose; 2) episodes of sneezing; 3) episodes of nose bleeds; 4) sinusitis or sinus problems; or 5) burning throat.

$\dagger \dagger$ Lower respiratory symptoms include one or more of the following: 1) cough attacks; 2) awoke with chest tightness; 3) awoke with shortness of breath; 4) chest wheezing or whistling; 5) asthma attack; 6) breathing trouble; 7) trouble with phlegm; or 8) shortness of breath on level ground or walking up a slight hill in past 12 months. \|Eye symptoms include watery, itchy, or sore eyes. 
$\overparen{\approx} \approx \overparen{\overbrace{}}$

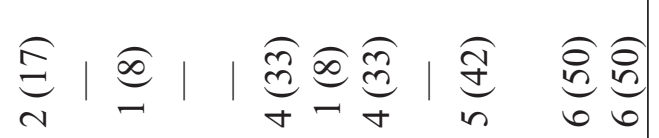

$$
\text { 西 }
$$

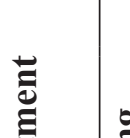

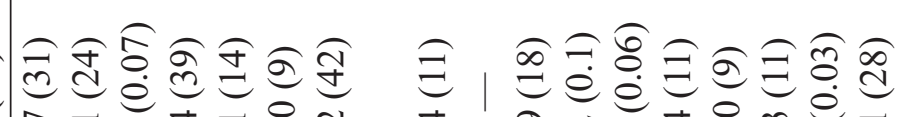

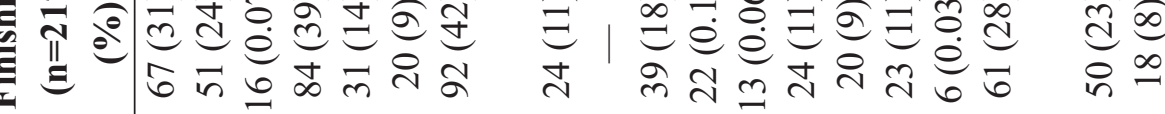

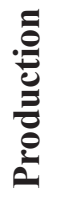


Table 6. Prevalence of reported respiratory diagnoses, NIOSH medical survey, June 2017 $\left(\mathrm{N}=364^{*}\right)$

\begin{tabular}{lc}
\hline \multicolumn{1}{c}{ Diagnosis } & Number (\%) \\
\hline Sinusitis or sinus infections & $84(23)$ \\
Hay fever or nasal allergies & $61(17)$ \\
Asthma & $31(9)$ \\
Chronic bronchitis & $21(6)$ \\
COPD & $5(1)$ \\
Emphysema & $3(0.8)$ \\
\hline
\end{tabular}

Note: NIOSH=National Institute for Occupational Safety and Health; N=number of participants; COPD = chronic obstructive pulmonary disease.

Work-related=better response to "when you are away from this plant on days off or on vacation, is the symptom: better, same or worse or yes response to "Is there anything at work that causes or aggravates the symptom"

*Number of employees who completed the questionnaire. 
Table 7. Lung function tests results of medical survey participants, NIOSH medical survey, June 2017

Number (\%)

Spirometry $(\mathrm{N}=345 *)$

Obstruction

Restriction

Mixed, n (\%)

Low $\mathrm{FEV}_{1}$, normal ratio and volume

$\mathrm{FEV}_{1} \%$ predicted, mean (range)

$99(49-134)$

FVC \% predicted, mean (range)

$99(56-134)$

$\mathrm{FEV}_{1} / \mathrm{FVC} \%$, mean (range)

$81(49-94)$

$\underline{\text { Impulse oscillometry }\left(\mathrm{N}=363^{+}\right)}$

Normal

Small airways abnormality

Large airways abnormality

Small and large airways abnormality

$\mathrm{R} 5 \mathrm{~Hz} \%$ predicted mean (range)

$\mathrm{R} 20 \mathrm{~Hz} \%$ predicted mean (range).

$\mathrm{X} 5$, mean, $\mathrm{kPa} /(\mathrm{L} / \mathrm{s})_{-}$

$-0.1$

R5-R20, mean (range)

$19(0-82)$

FENO $\left(\mathrm{N}=347^{\S}\right)$

Normal

Elevated

$15(4)$

Note: NIOSH=National Institute for Occupational Safety and Health; N=number of participants; FEV1=forced expiratory volume in one second; $\mathrm{FVC}=$ forced vital capacity; $\mathrm{R5}=$ resistance at $5 \mathrm{Hertz}$; R5-R20=difference between resistance at 5 and $20 \mathrm{Hertz} ; \mathrm{R} 20=$ resistance at $20 \mathrm{Hertz}$; X $=$ reactance at $5 \mathrm{Hertz} ; \mathrm{kPa} /(\mathrm{L} / \mathrm{s})=\mathrm{kilopascals}$ per liter per second; FENO= fractional exhaled nitric oxide.

* Number of employees who completed spirometry.

\$ Number of employees who completed impulse oscillometry.

§Number of employees who completed FENO. 


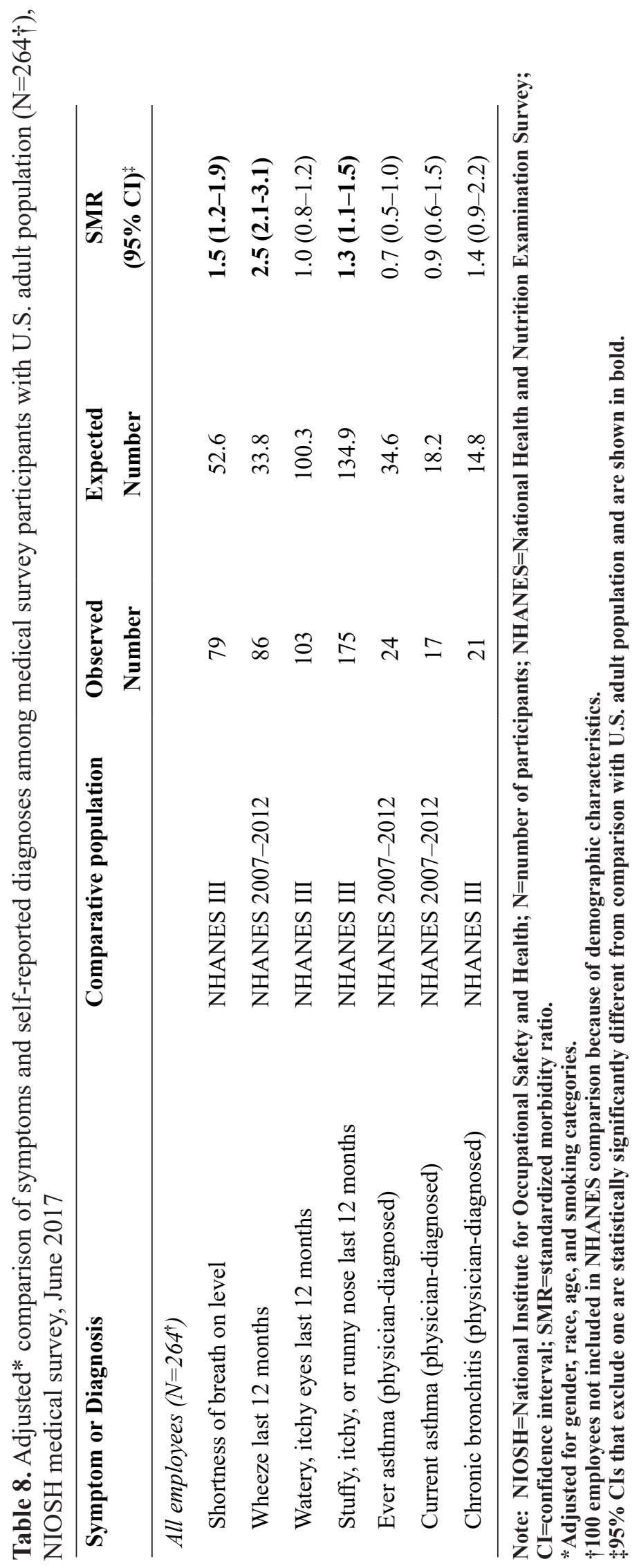




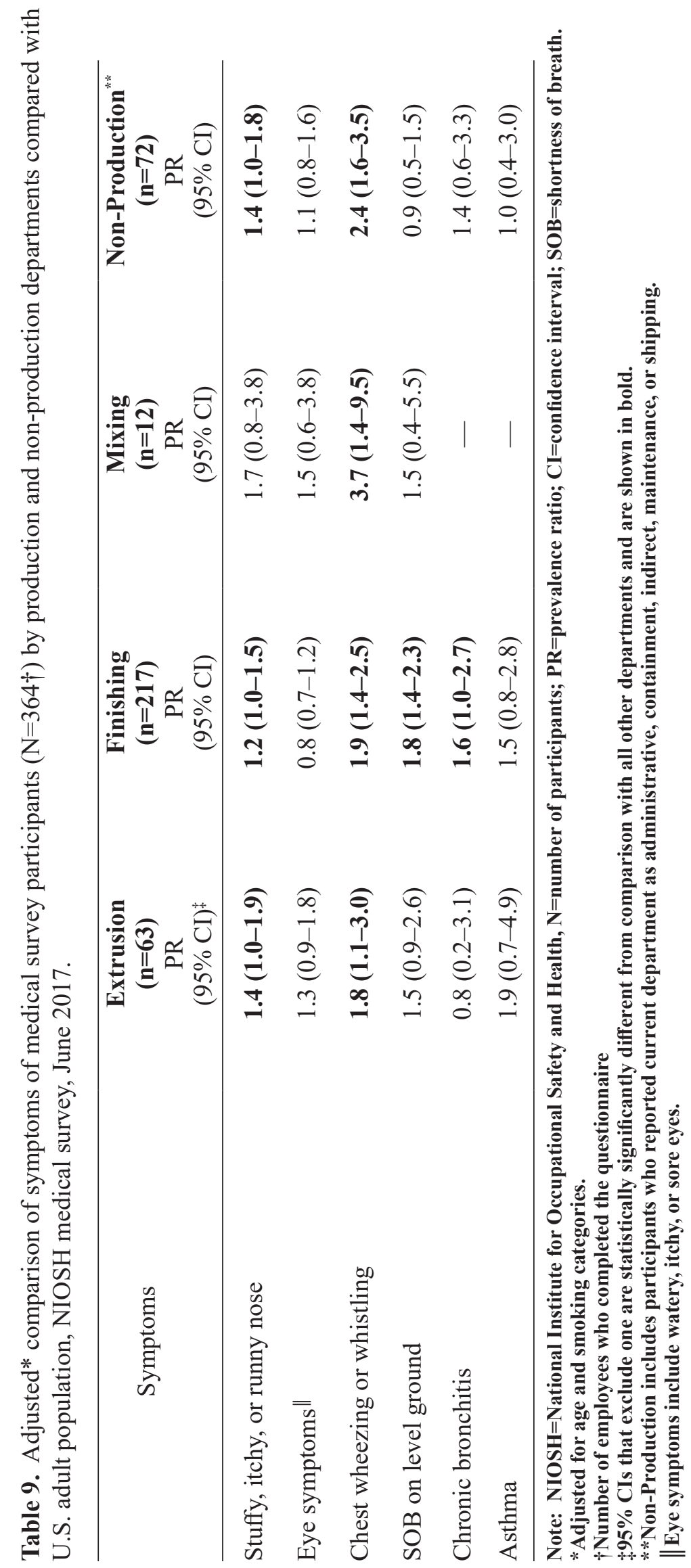


Table 10. Adjusted* comparisons of spirometric results among NIOSH medical survey participants $(\mathrm{N}=250)^{*}$ with U.S. adult population, NIOSH medical survey, June 2017.

\begin{tabular}{llll}
\hline Test result & Observed & Expected & SMR (95\% CI) \\
Obstruction pattern & 6 & 8.3 & $0.7(0.3-1.6)$ \\
Restriction pattern & 13 & 22.1 & $0.6(0.3-1.0)$ \\
Mixed & 2 & 4.4 & $0.5(0.1-1.7)$ \\
\hline
\end{tabular}

Note: NIOSH=National Institute for Occupational Safety and Health;

*102 employee not included in National Health and Nutrition Examination Survey comparison because of demographic characteristics. 


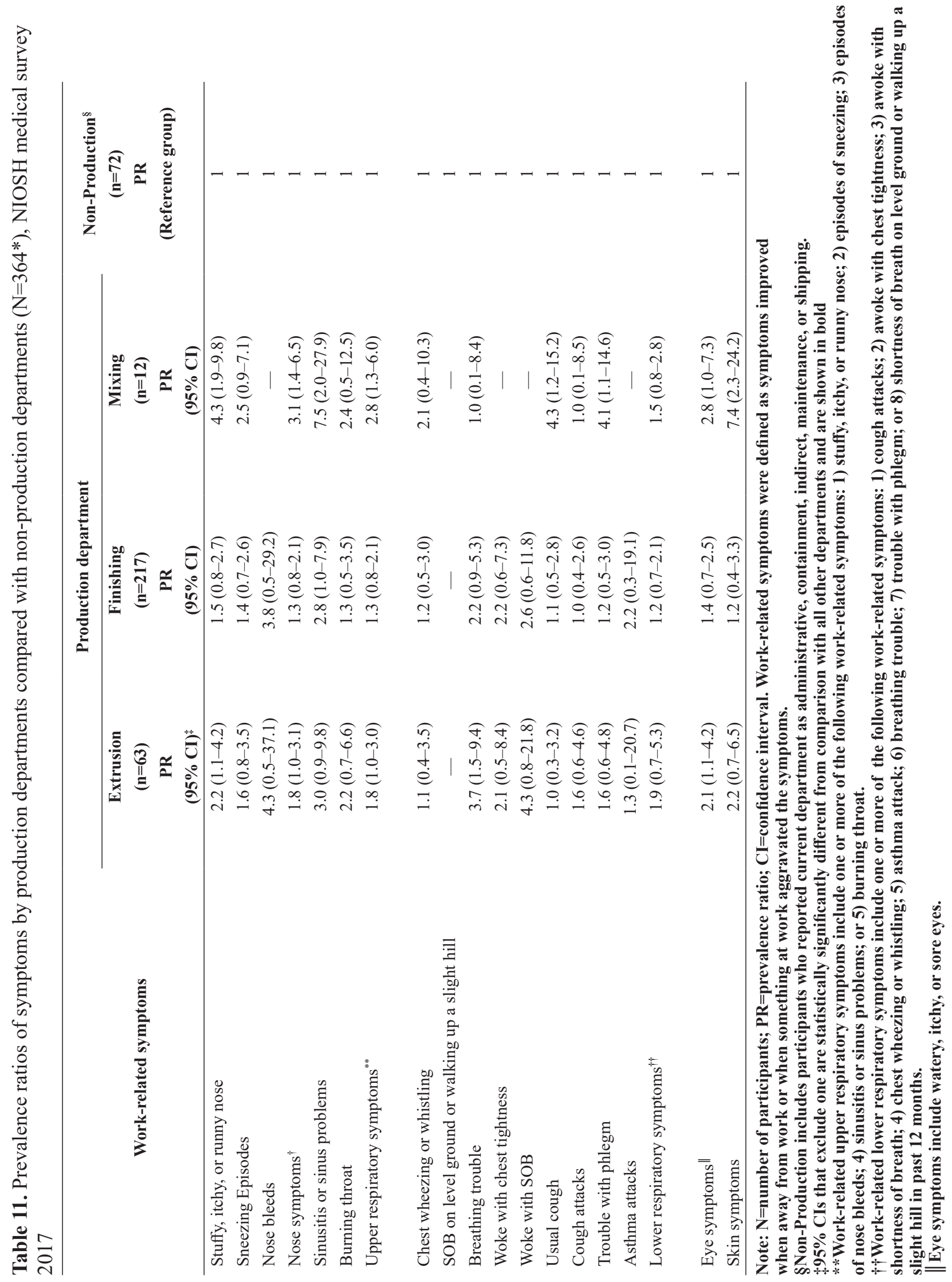




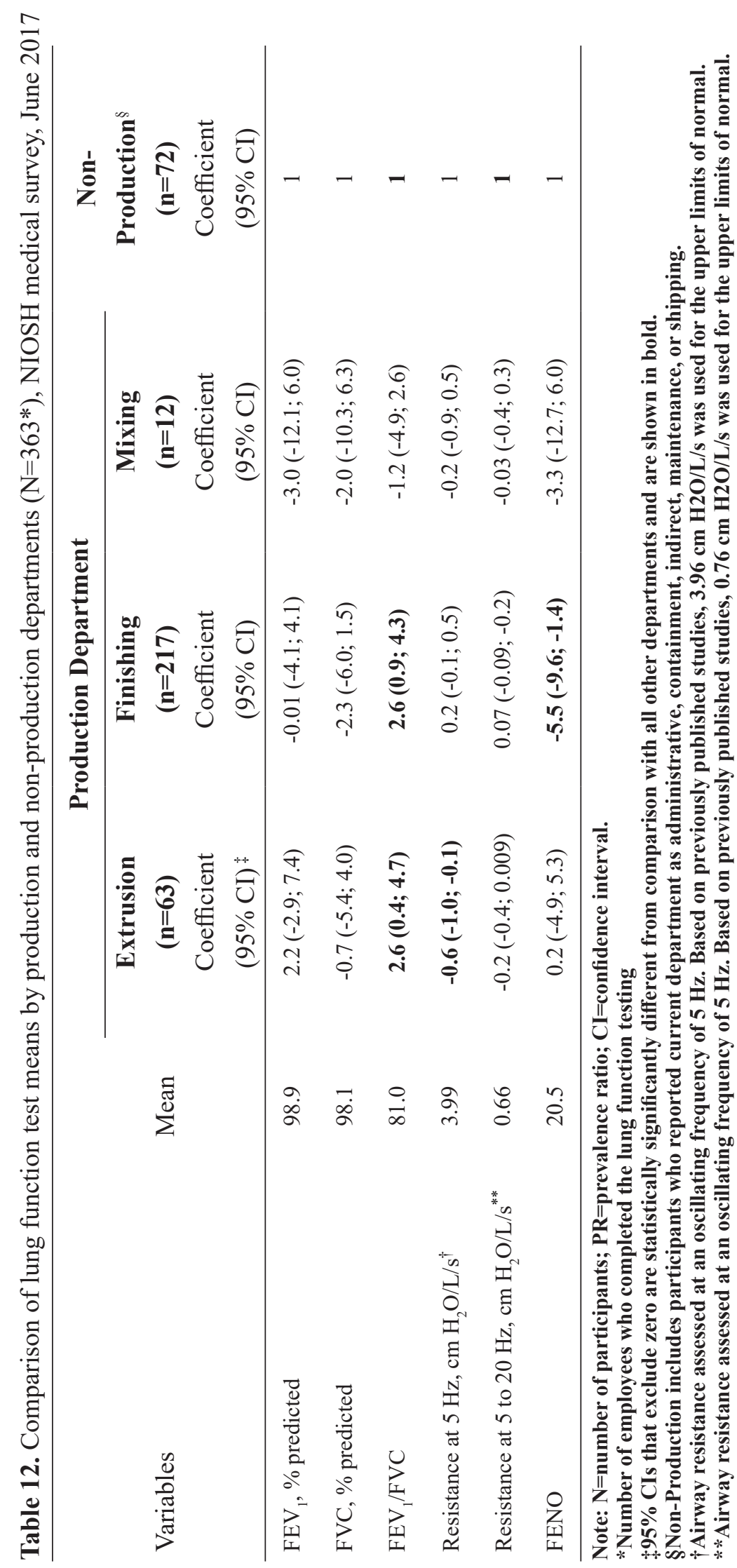




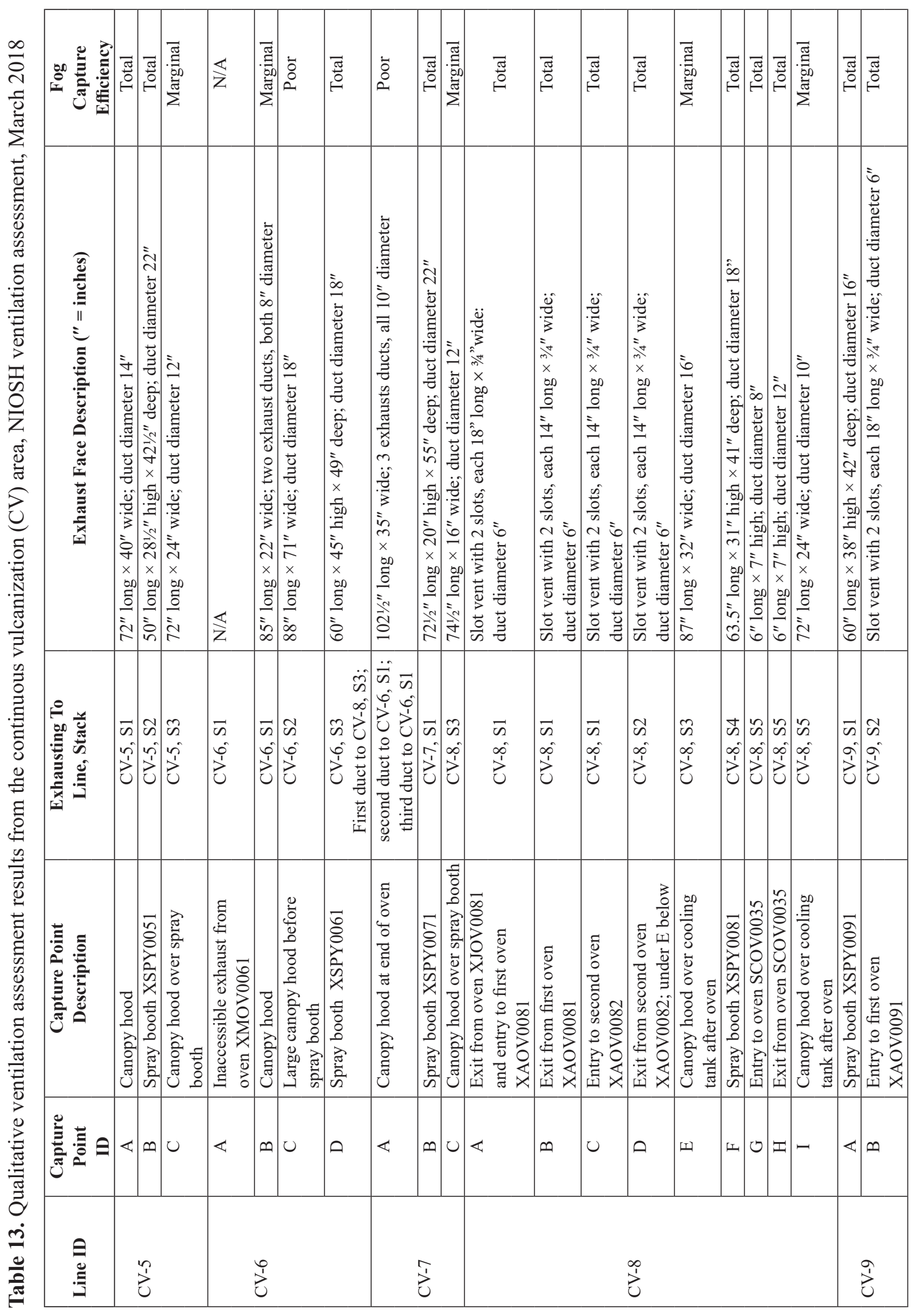




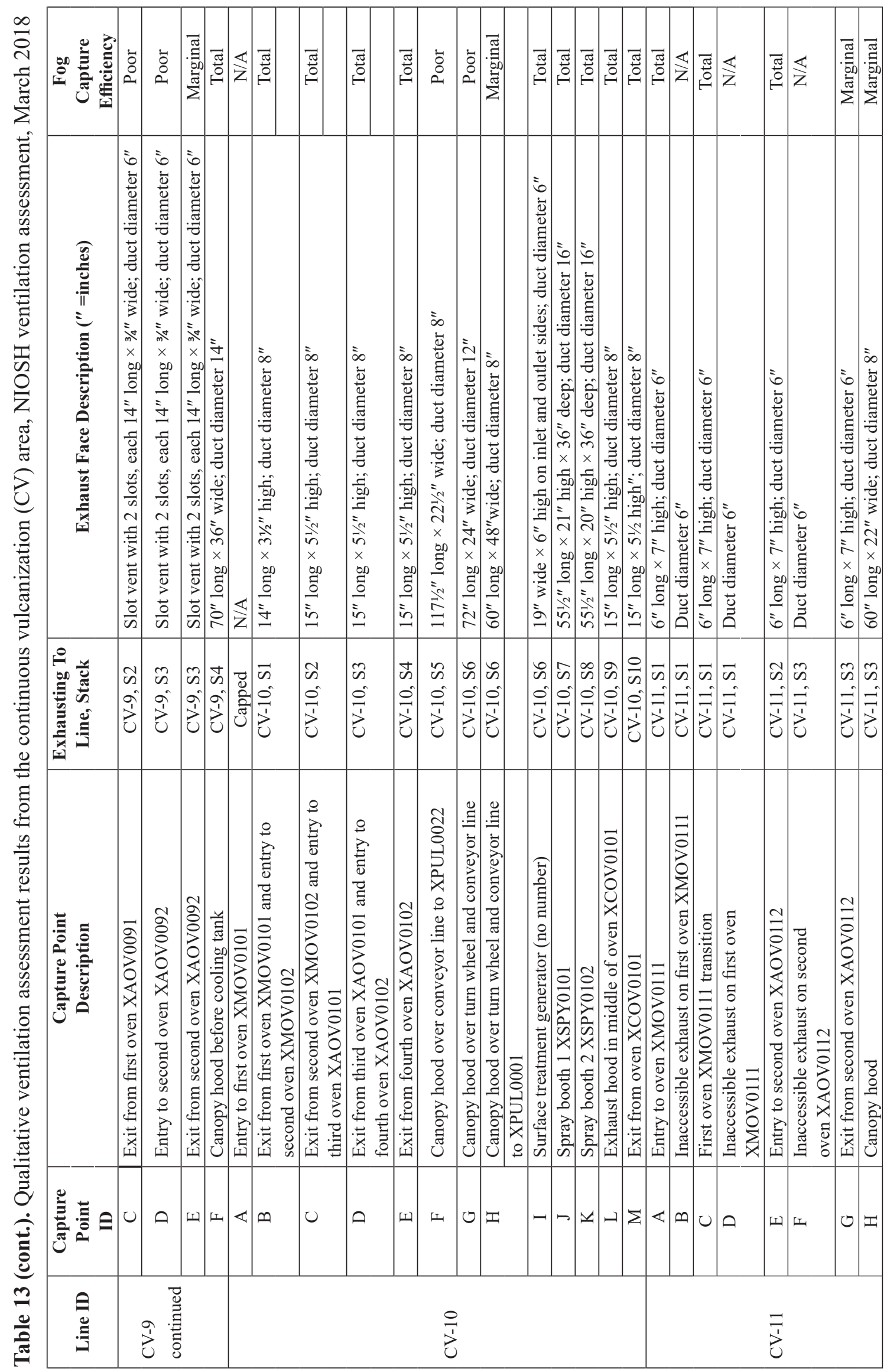




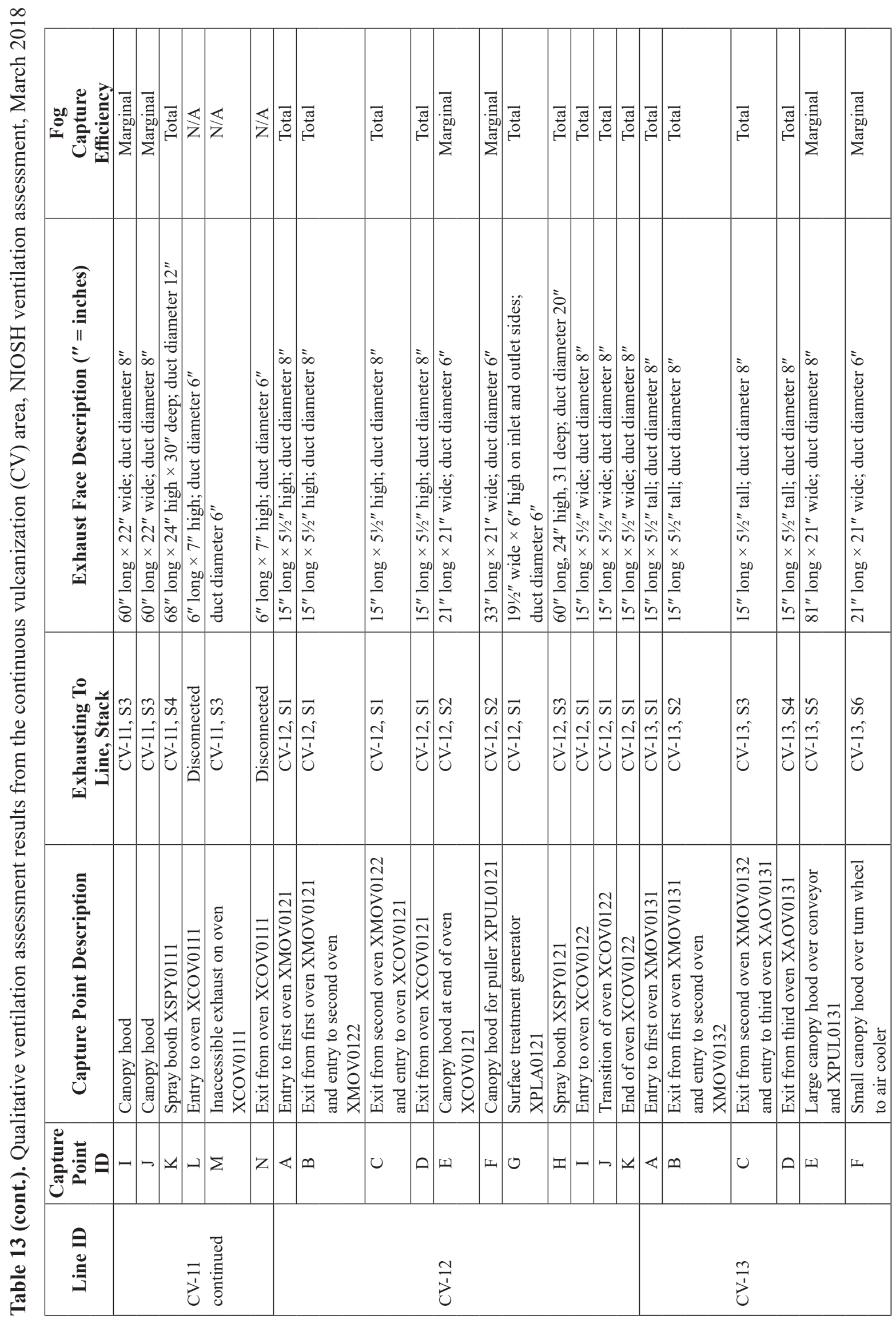




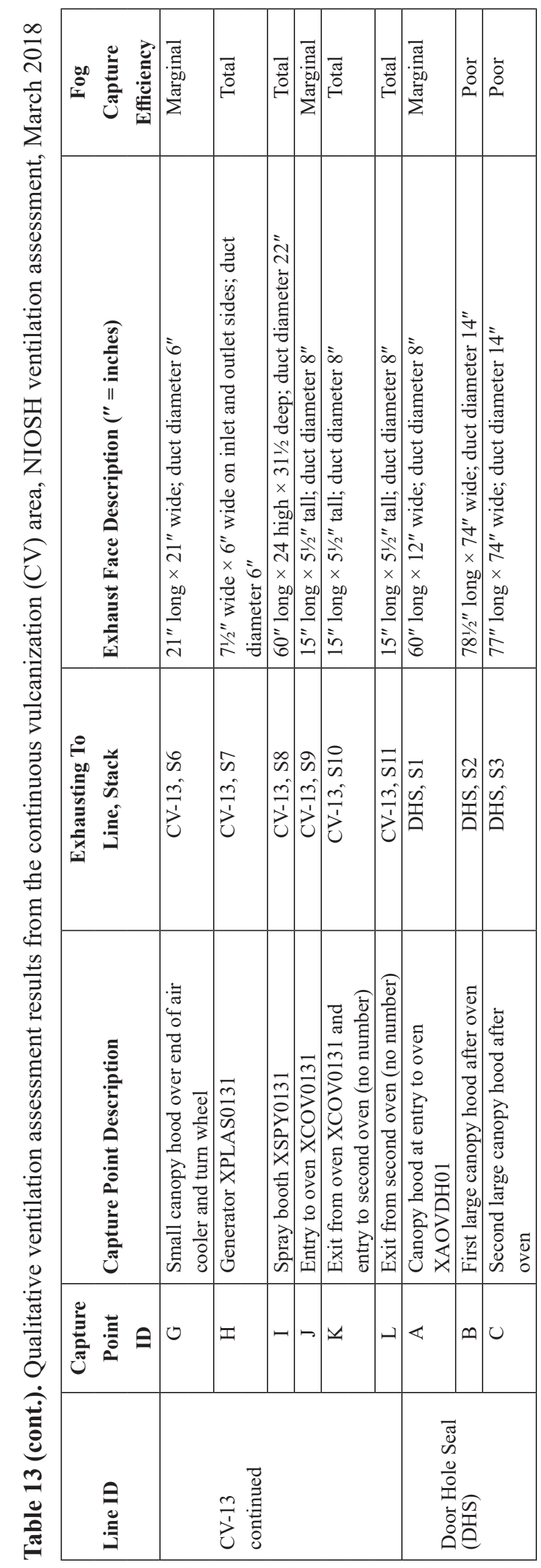




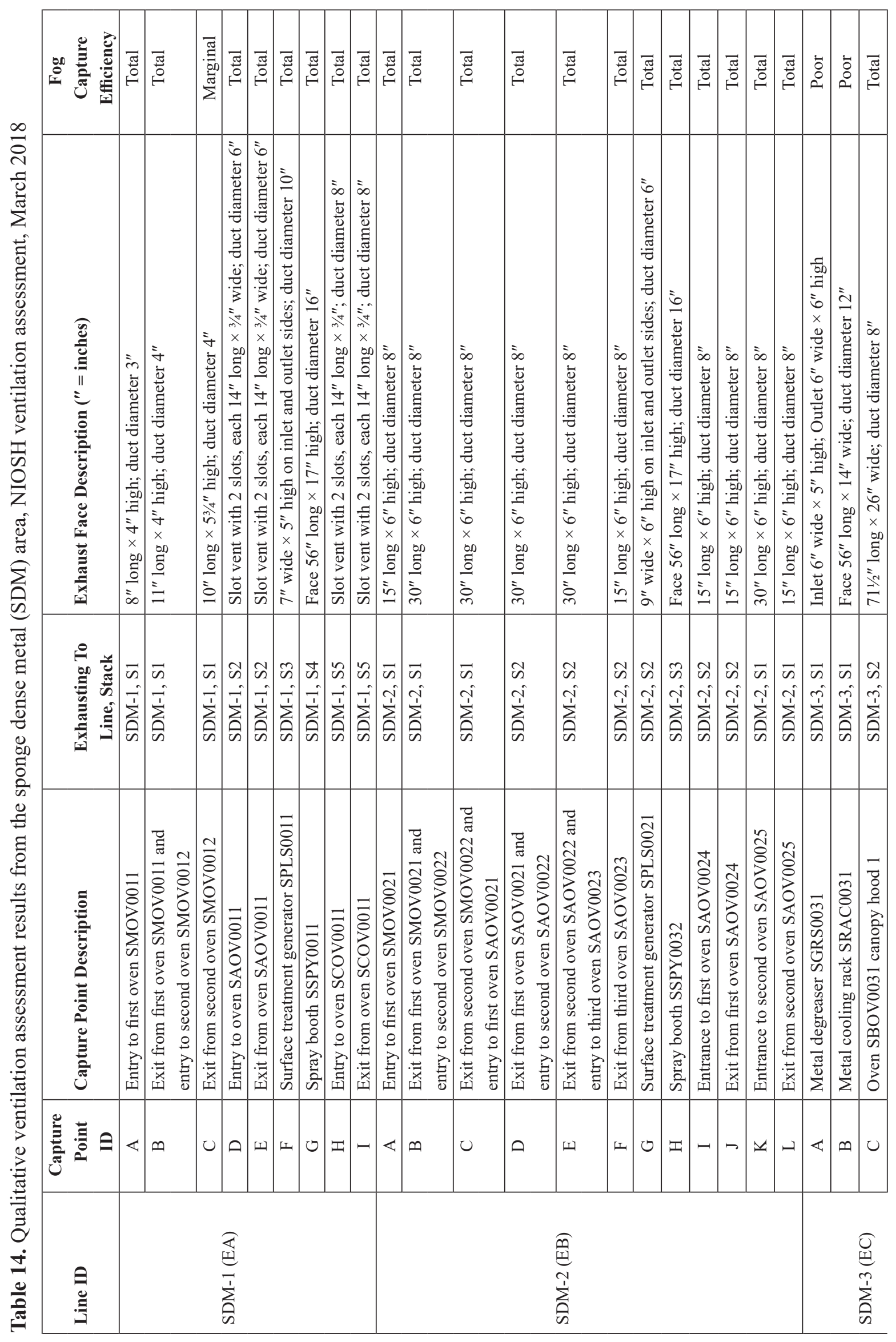




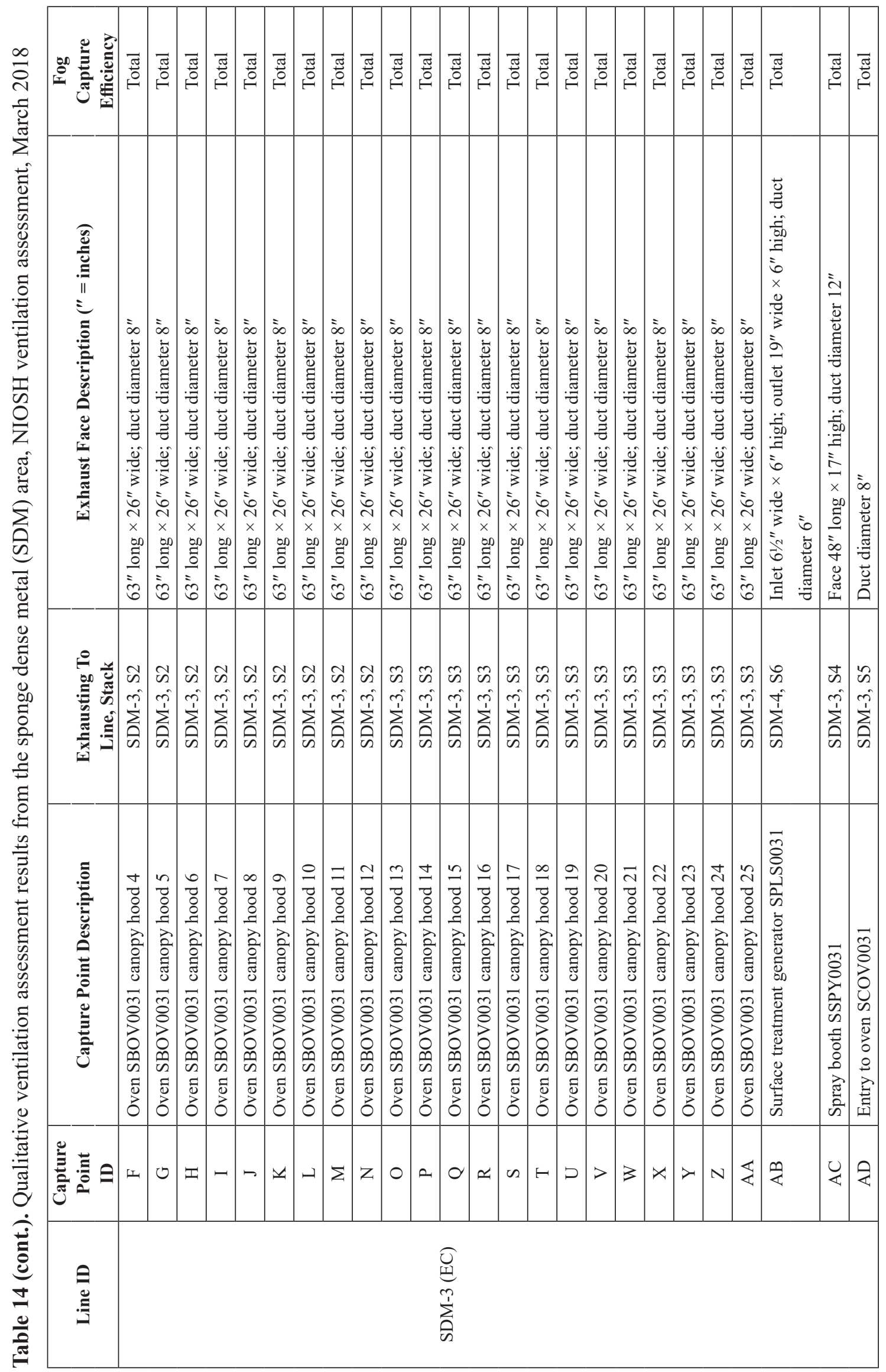




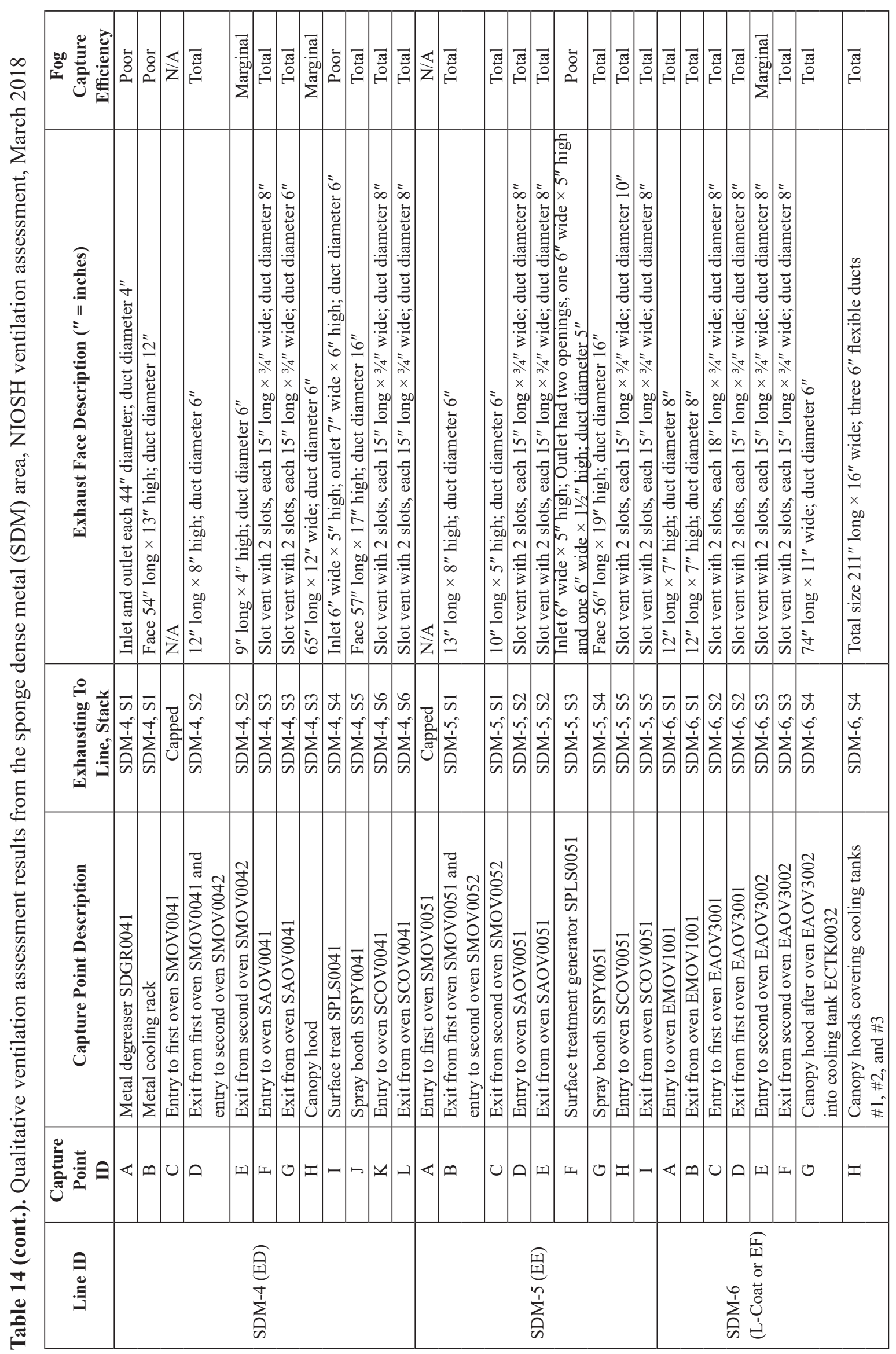




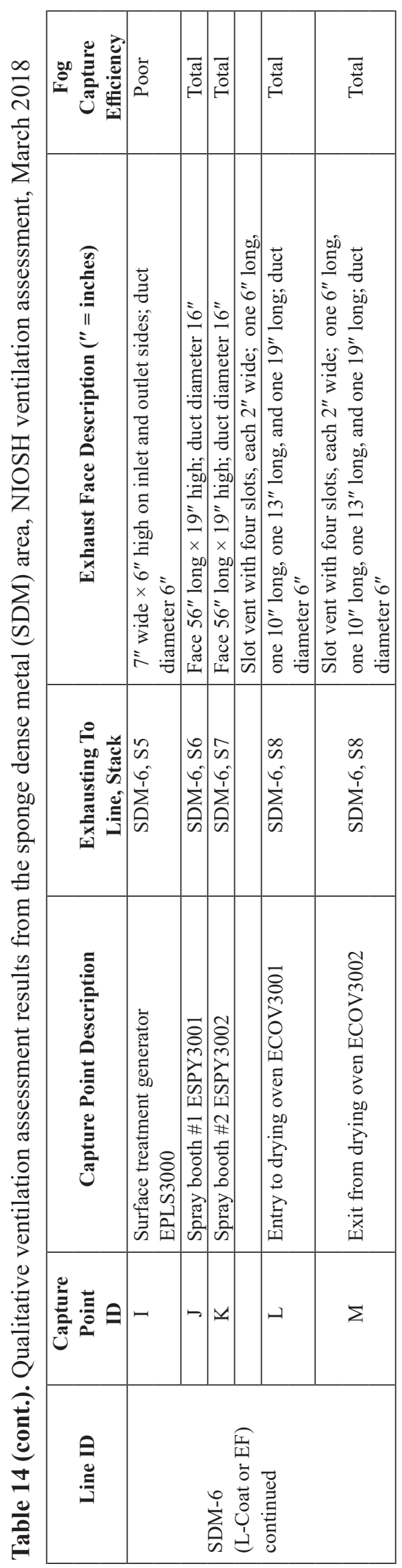




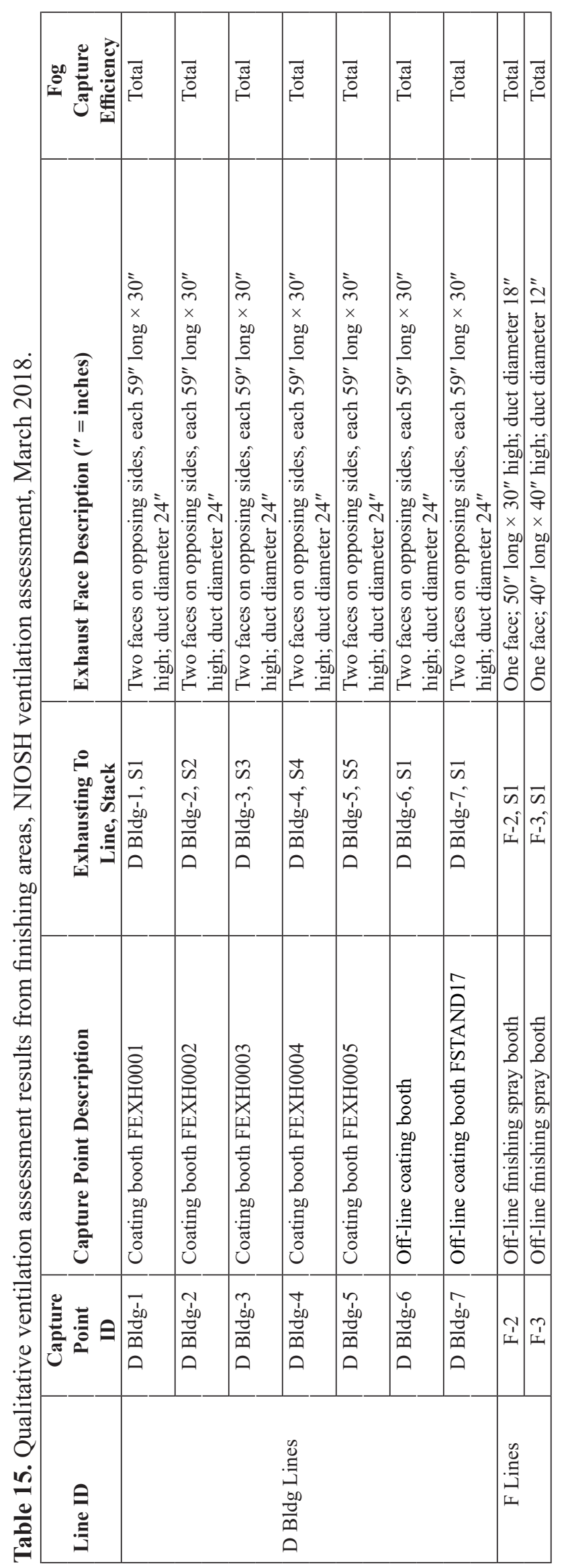




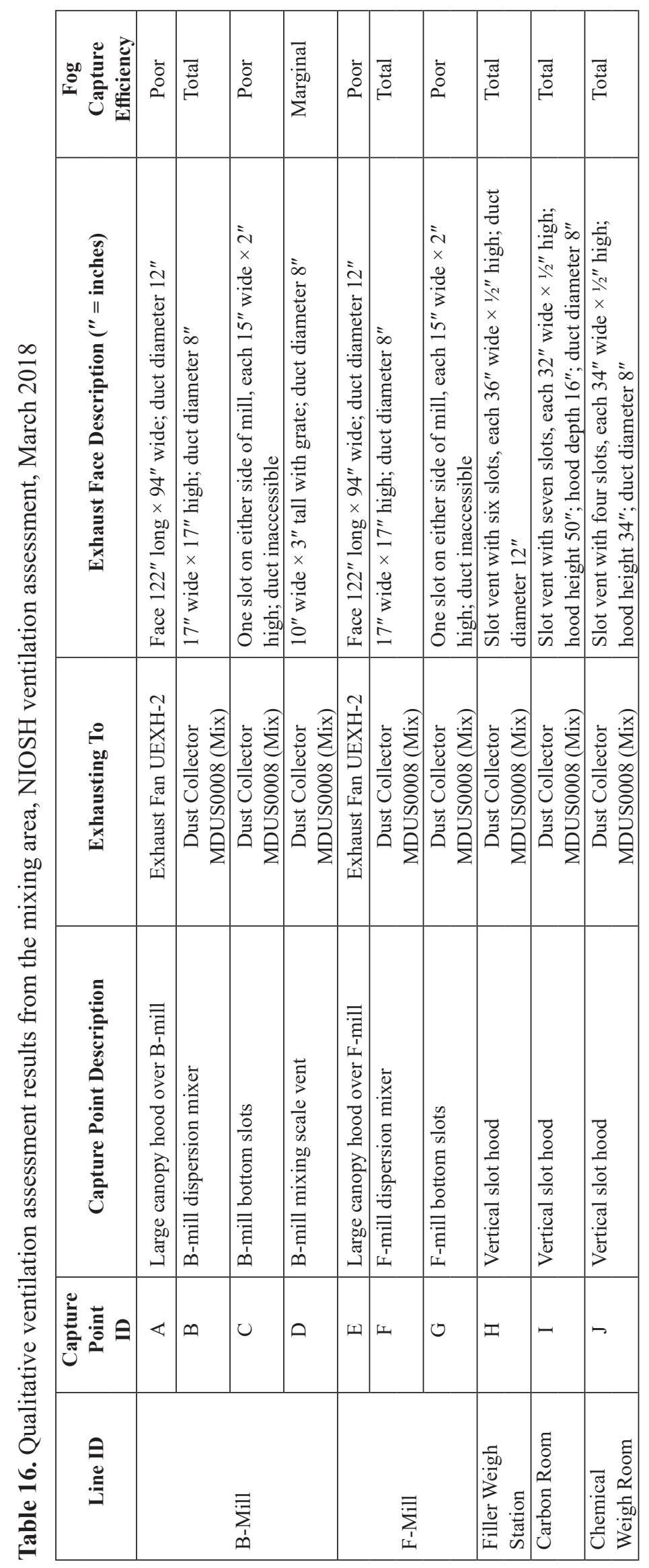


Table 17. Pressure relationships between two adjacent spaces, NIOSH ventilation assessment, March 2018.

\begin{tabular}{|l|c|l|}
\hline Negative Pressure Space & Direction of Air Flow & Positive Pressure Space \\
\hline Chemical Weigh Station & $\leftarrow$ & CV Area \\
\hline Carbon Black Room & $\leftarrow$ & Mixing Area \\
\hline Oil Storage Room & $\leftarrow$ & CV Area \\
\hline SDM Area & $\leftarrow$ & Mezzanine above SDM Area \\
\hline CV Area & $\leftarrow$ & Training Room and Mezzanine above CV Area \\
\hline Finishing Area & $\leftarrow$ & Employee Break Room \\
\hline CV Area & $\leftarrow$ & First Aid Room \\
\hline
\end{tabular}

Note: $\mathrm{CV}=$ continuous vulcanization; $\mathrm{SDM}=$ sponge dense metal. 


\section{References}

ACGIH [2019]. 2019 TLVs ${ }^{\circledR}$ and BEIs ${ }^{\circledR}$ : Threshold limit values for chemical substances and physical agents and biological exposure indices. Cincinnati, $\mathrm{OH}$ : American Conference of Governmental Industrial Hygienists.

Akca ASD, Demircan N, Kart L, Altin R [2011]. Evaluation of respiratory symptoms in workers of a rubber factory. Eur J Gen Med 8(4):302-307, https://doi.org/10.29333/ ejgm/82759.

Alessio L [1996]. Multiple exposure to solvents in the workplace. Int Arch of Occup Environ Health 69:1-4, https://doi.org/10.1007/bf02630731.

Alexandersson R. Gustafsson P, Hedenstierna G, Rosen G [1986]. Exposure to naphthalenediisocyanate in a rubber plant: symptoms and lung function. Arch Environ Health 41:85-89, https://doi.org/10.1080/00039896.1986.9937414.

Attarchi M, Dehghan F, Afrasyabi M, Sadeghi Z, Mohammadi S [2013]. Combined effect of cigarette smoking and occupational exposures on lung function: a cross-sectional study of rubber industry workers. Workplace Health Saf 61(5):213-220, https://doi. org/10.1177/216507991306100505.

Balmes J, Becklake M, Blanc P, Henneberger P, Kreiss K, Mapp C, Milton D, Schwartz D, Toren K, Viegi G [2003]. American Thoracic Society Statement: Occupational contribution to the burden of airway disease. Am J Respir Crit Care Med 167(5):787-797, https://doi. org/10.1164/rccm.167.5.787.

Bang KM, Syamlal G, Mazurek JM, Wassell JT [2013]. Chronic obstructive pulmonary disease prevalence among nonsmokers by occupation in the United States. J Occup Environ Med 55(9):1021-1026, https://doi.org/10.1097/JOM.0b013e31829baa97.

Bascom R, Fisher JF, Thomas RJ, Yang WN, Baser ME, Baker JH [1988]. Eosinophilia, respiratory symptoms and pulmonary infiltrates in rubber workers. Chest 93(1):154-158, https://doi.org/10.1378/chest.93.1.154.

Bascom R, Baser ME, Thomas RJ, Fisher JF, Yang WN, Baker JH [1990]. Elevated serum IgE, eosinophilia, and lung function in rubber workers. Arch Environ Health 45(1):15-19, https://doi.org/10.1080/00039896.1990.9935918.

Blanc PD, Toren K [2007]. Occupation in chronic obstructive pulmonary disease and chronic bronchitis: an update. Int J Tuberc Lung Dis 11(3):251-257, https://www.ingentaconnect. com/content/iuatld/ijtld/2007/00000011/00000003/art00006.

Blanc PD [2012]. Occupation and COPD: a brief review. J Asthma 49(1): 2-4, https://doi.org/ 10.3109/02770903.2011.611957. 
Blanc PD, Annesi-Maesano I, Balmes JR, Cummings KJ, Fishwick D, Miedinger D, Murgia N, Naidoo RN, Reynolds CJ, Sigsgaard T, Toren K, Vinnikov D, Redlich CA [2019]. The Occupational Burden of Nonmalignant Respiratory Disease, An Official American Thoracic Soceity and European Respiratory Society Statement. Am J Respir Crit Care Med 199(11):1312-1334.

Burney P, Chinn S [1987]. Developing a new questionnaire for measuring the prevalence and distribution of asthma. Chest 91(6 Suppl):79S-83S, https://doi.org/10.1378/chest.91.6 supplement.79s.

Burney PG, Laitinen LA, Perdrizet S, Huckauf H, Tattersfield AE, Chinn S, Poisson N, Heeren A, Britton JR, Jones T [1989]. Validity and repeatability of the IUATLD (1984) Bronchial symptoms questionnaire: an international comparison. Eur Respir J 2(10):940-945.

Burney PG, Luczynska C, Chinn S, Jarvis D [1994]. The European community respiratory health survey. Eur Respir J 7(5):954-960, https://doi.org/10.1183/09031936.94.07050954.

CDC [1996]. Third National Health and Nutrition Examination Survey, 1988-1994, NHANES III Examination Data File. Hyattsville, Maryland: U.S. Department of Health and Human Services, Centers for Disease Control and Prevention, https://wwwn.cdc.gov/nchs/ nhanes/nhanes3/default.aspx.

CDC [2018a]. National Center for Health Statistics. National Health and Nutrition Examination Survey Data. Hyattsville, MD: U.S. Department of Health and Human Services, Centers for Disease Control and Prevention, [2007-2012], https:/wwwn.cdc.gov/nchs/ nhanes/default.aspx.

CDC [2018b]. Smoking \& tobacco use: quit smoking. https://www.cdc.gov/tobacco/ stateandcommunity/tobacco_control programs/index.htm

CFR. Code of Federal Regulations. Washington, DC: U.S. Government Printing Office, Office of the Federal Register.

doPico GA, Rankin J, Chosy LW, Reddan WG, Barbee RA, Gee B, Dickie HA [1975]. Respiratory tract disease from thermosetting resins. Study of an outbreak in rubber tire workers. Ann Intern Med 83(2):177-184, https://doi.org/10.7326/0003-4819-83-2-177.

Dweik RA, Boggs PB, Erzurum SC, Irvin CG, Leigh MW, Lundberg JO, Olin AC, Plummer AL, Taylor DR; American Thoracic Society Committee on Interpretation of Exhaled Nitric Oxide Levels (FENO) for Clinical Applications [2011]. An official ATS clinical practice guideline: interpretation of exhaled nitric oxide levels (FENO) for clinical applications. Am J Respir Crit Care Med 184(5):602-615, https://doi.org/10.1164/rccm.9120-11ST.

EAACI Task Force on Occupational Rhinitis, Moscato G, Vandenplas O, Gerth Van Wijk 
R, Malo JL, Quirce S, Walusiak J, Castano R, De Groot H, Folletti I, Gautrin D, Yacoub MR, Perfetti L, Siracusa A [2008]. Occupational rhinitis. Allergy 63(8):969-980, https://doi. org/10.1111/j.1398-9995.2008.01801.x.

ECRHS [2014]. Questionnaires, protocols and instructions. European Community Respiratory Health Survey, http://www.ecrhs.org/Quests.htm.

EPA [1999]. Compendium of methods for the determination of toxic organic compounds in ambient air: Compendium method TO-17 - Determination of volatile organic compounds in ambient air using active sampling onto sorbent tubes, Second Edition. Cincinnati, $\mathrm{OH}$ : Environmental Protection Agency, Center for Environmental Research Information, Office of Research and Development, https:/www3.epa.gov/ttnamti1/files/ambient/airtox/to-17r.pdf.

EPA [2018]. Integrated Science Assessment (ISA) for Particulate Matter (External Review Draft). U.S. Environmental Protection Agency, Washington, DC, https://cfpub.epa.gov/ncea/

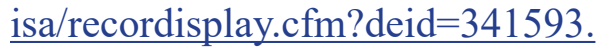

Evans EA [1973]. Pulmonary edema after inhalation of fumes from polytetrafluoroethylene (PTFE). J Occup Med 15:1-9.

Ferris BG [1978]. Epidemiology standardization project (American Thoracic Society). Am Rev Respir Dis 118(6 pt 2):1-20.

Fine LJ, Peters JM [1976a]. Respiratory morbidity in rubber workers: I. Prevalence of respiratory symptoms and disease in curing workers. Arch Environ Health 31(1):5-9.

Fine LJ, Peters JM [1976b]. Respiratory morbidity in rubber workers: II. Pulmonary function in curing workers. Arch Environ Health 31(1):10-14.

Fine LJ, Peters JM [1976c]. Studies of respiratory morbidity in rubber workers: Part III. Respiratory morbidity in processing workers. Arch Environ Health 31(3):136-140.

Fine LJ, Peters JM, Burgess WA, Di Berardinis LJ [1976]. Studies of respiratory morbidity in rubber workers. Part IV. Respiratory morbidity in talc workers. Arch Environ Health 31(4):195-200.

Fishwick D, Darby A, Hnizdo E, Barber C, Sumner J, Barraclough R, Bolton C, Burge S, Calverley P, Hopkinson N, Hoyle J, Lawson R, Niven R, Pickering T, Prowse K, Reid P, Warburton C, Blanc PD [2013]. COPD causation and workplace exposures: an assessment of agreement among expert clinical raters. COPD 10(2):172-179, https://doi.org/10.3109/15412 $\underline{555.2012 .737072 .}$

Fox RW, Lockey RF [2003]. The impact of rhinosinusitis on asthma. Curr Allergy Asthma Rep 3(6):513-518, https://doi.org/10.1007/s11882-003-0063-0. 
Friedman SM, Maslow CB, Reibman J, Pillai PS, Goldring RM, Farfel MR, Stellman SD, Berger KI [2011]. Case-control study of lung function in world trade center health registry area residents and workers. Am J Respir Crit Care Med 184: 582-589, https://doi.org/10.1164/ recm.201011-19090C.

Froneberg B, Johnson PL, Landrigan PJ [1982]. Respiratory illness caused by overheating of polyvinyl chloride. Br J Ind Med 39(3):239-243, https://doi.org/10.1136/oem.39.3.239.

Gamble JF, McMichael AJ, Williams T, Battigelli M [1976]. Respiratory function and symptoms: an environmental-epidemiological study of rubber workers exposed to a phenolformaldehyde type resin. Am Ind Hyg Assoc J 37(9):499-513, https://doi. org $/ 10.1080 / 0002889768507508$.

Governa M, Comai M, Valentino M, Antonicelli L, Rinaldi F, Pisani E [1987]. Ventilatory function in rubber processing workers: acute changes over the workshift. Br J Ind Med 44(2):83-89, https://doi.org/10.1136/oem.44.2.83.

Guerra S, Sherrill DL, Martinez FD, Barbee RA [2002]. Rhinitis as an independent risk factor for adult-onset asthma. J Allergy Clin Immun 109(3):419-425, https://doi.org/10.1067/ mai.2002.121701.

Gupta P, Banerjee DK, Bhargava SK, Kaul R, Shankara VR [1993]. Effect of Pollutants on Airway Resistance in Rubber Factory Workers. Indoor Built Environ 2(2):105-110, https:// journals.sagepub.com/doi/pdf/10.1177/1420326X9300200206.

Halldin CN, Doney BC, Hnizdo E [2015]. Changes in prevalence of chronic obstructive pulmonary disease and asthma in the US population and associated risk factors. Chron Respir Dis 12(1):47-60, https://doi.org/10.1177/1479972314562409.

Hankinson JL, Odencrantz JR, Fedan KB [1999]. Spirometric reference values from a sample of the general U.S. population. Am J Respir Crit Care Med 159(1):179-187, https://doi. org/10.1164/ajrccm.159.1.9712108.

Haponik E, Summer W [1981]. Inhalation of irritant gases. Clin Chest Med 2(2):273-287, https://doi.org/10.1007/978-1-4684-0347-3 30.

Hnizdo E, Sullivan PA, Bang KM, Wagner G [2002]. Association between chronic obstructive pulmonary disease and employment by industry and occupation in the US population: a study of data from the Third National Health and Nutrition Examination Survey. Am J Epidemiol 156(8):738-746, https://doi.org/10.1093/aje/kwf105.

Jonsson LS, Broberg K, Axmon A, Jonsson BAG, Littorin M [2007]. Symptoms and immunologic markers among vulcanization workers in rubber industries in southern Sweden. Scand J Work Environ Health 33(4):272-279, https://doi.org/10.5271/sjweh.1143. 
Jonsson LS, Jonsson BA, Axmon A, Littorin M, Broberg K [2008]. Influence of glutathionerelated genes on symptoms and immunologic markers among vulcanization workers in the southern Sweden rubber industries. Int Arch Occup Environ Health 81(7):913-919, https:// doi.org/10.1007/s00420-007-0285-X.

Jonsson LS, Lindh CH, Bergendorf U, Axmon A, Littorin M, Jonsson BA [2009]. $\mathrm{N}$-nitrosamines in the southern Swedish rubber industries - exposure, health effects, and immunologic markers. Scand J Work Environ Health 35(3):203-211, https://doi.org/10.5271/ sjweh.1323.

Kato T, Ieki R [2005]. A case of acute eosinophilic pneumonia associated with heated rubber fume exposure. Allergol Int 54(3):491-494, https://doi.org/10.2332/allergolint.54.491.

Kim H, Herbert R, Landrigan P, Markowitz SB, Moline JM, Savitz DA, Todd AC, Udasin IG, Wisnivesky JP [2012]. Increased rates of asthma among World Trade Center disaster responders. Am J Ind Med 55(1):44-53, https://doi.org/10.1002/ajim.21025.

King MS, Eisenberg R, Newman JH, Tolle JJ, Harrell FE Jr, Nian H, Ninan M, Lambright ES, Sheller JR, Johnson JE, Miller RF [2011]. Constrictive bronchiolitis in soldiers returning from Iraq and Afghanistan. N Engl J Med. 365(3):222-230, https://doi.org/10.1056/ NEJMoa1101388.

Koh YY, Kim CK [2003]. The development of asthma in patients with allergic rhinitis. Curr Opin Allergy Clin. 3(3):159-164, https://doi.org/10.1097/01.all.0000072711.82112.4b.

Korn RJ, Dockery DW, Speizer FE, Ware JH, Ferris BG [1987]. Occupational exposures and chronic respiratory symptoms. Am Rev Respir Dis 135(suppl):A342.

Krouse J, Brown R, Fineman S, Han J, Heller A, Joe S, Krouse H, Pillsbury H 3rd, Ryan M, Veling M [2007]. Asthma and the unified airway. Otolaryng Head Neck. 136:S75-S106, https://doi.org/10.1016/j.otohns.2007.02.019.

Kuntz WD, McCord CP [1974]. Polymer-fume fever. J Occup Med 15:599-601.

Lange P, Groth S, Nyboe J, Appleyard M, Mortensen J, Jensen G, Schnohr P [1989]. Chronic obstructive lung disease in Copenhagen: cross-sectional epidemiological aspects. J Intern Med 226(1):25-32, https://doi.org/10.1111/j.1365-2796.1989.tb01349.x.

Lednar WM, Tyroler HA, McMichael AJ, Shy CM [1977]. The occupational determinants of chronic disabling pulmonary disease in rubber workers. J Occup Med 19(4):263-268, https:// doi.org/10.1097/00043764-197704000-00007.

Lindberg A, Jonsson AC, Ronmark E, Lundgren R, Larsson LG, Lundback B [2005]. Tenyear cumulative incidence of COPD and risk factors for incident disease in a symptomatic cohort. Chest 127(5):1544-1552, https://doi.org/10.1378/chest.127.5.1544. 
McMichael AJ, Gerber WS, Gamble JF, Lednar WM [1976]. Chronic respiratory symptoms and job type within the rubber industry. J Occup Med 18(9):611-617.

Meijer E, Heederik D, Kromhout H [1998]. Pulmonary effects of inhaled dust and fumes: exposure-response study in rubber workers. Am J Ind Med 33(1):16-23, https://doi. org/10.1002/(sici)1097-0274(199801)33:1\%3C16::aid-ajim3\%3E3.0.co;2-u.

Miller MR, Hankinson J, Brusasco V, Burgos F, Casaburi R, Coates A, Crapo R, Enright P, van der Grinten CP, Gustafsson P, Jensen R, Johnson DC, MacIntyre N, McKay R, Navajas D, Pedersen OF, Pellegrino R, Viegi G, Wanger J, ATS/ERS Task Force [2005]. Standardisation of spirometry. Eur Respir J 26(2):319-338, https://doi.org/10.1183/09031936 .05 .00034805 .

Moscato G, Rampulla C [2003]. Cost of occupational asthma and of occupational chronic obstructive pulmonary disease. Curr Opin in Allergy Clin Immunol 3(2):109-114, https://doi. org/10.1097/01.all.0000064774.57552.a0.

Neghab M, Rahimi E, Emad A, Rajaeei Fard AR [2007]. An epidemiological study of talcrelated respiratory morbidity among employees of a rubber industry in Shiraz-Iran. Int Arch Occup Environ Health 80(6):539-546, https://doi.org/10.1007/s00420-006-0161-0.

Neghab M, Mohraz MH, Hassanzadeh J [2011]. Symptoms of respiratory disease and lung functional impairment associated with occupational inhalation exposure to carbon black dust. J Occup Health 53(6):432-438, https://doi.org/10.1539/joh.11-0083-oa.

NIOSH [1996]. NIOSH manual of analytical methods (NMAM). 4th ed. Cincinnati, OH: U.S. Department of Health and Human Services, Centers for Disease Control and Prevention, National Institute for Occupational Safety and Health, Publication No. 94-113 (August 1994); 1st Supplement Publication 96-135, 2nd Supplement Publication 98-119; 3rd Supplement 2003-154, http:/www.cdc.gov/niosh/docs/2003-154/pdfs/2549.pdf.

NIOSH [2004]. NIOSH respirator selection logic. Cincinnati, OH: U.S. Department of Health and Human Services, Centers for Disease Control and Prevention, National Institute for Occupational Safety and Health, Publication No. 2005-100 https://www.cdc.gov/niosh/ docs/2005-100/pdfs/2005-100.pdf.

NIOSH [2016]. NIOSH criteria for a recommended standard: occupational exposure to heat and hot environments. By Jacklitsch B, Williams WJ, Musolin K, Coca A, Kim J-H, Turner N. Cincinnati, OH: U.S. Department of Health and Human Services, Centers for Disease Control and Prevention, National Institute for Occupational Safety and Health, DHHS (NIOSH) Publication 2016-106, https://www.cdc.gov/niosh/docs/2016-106/default.html.

NIOSH [2018]. Heat stress. U.S. Department of Health, Education, and Welfare, Center for Disease Control, National Institute for Occupational Safety and Health, https://www.cdc.gov/ niosh/topics/heatstress/default.html. 
Oppenheimer BW, Goldring RM, Herberg ME, Hofer IS, Reyfman PA, Liautaud S, Rom WN, Reibman J, Berger KI [2007]. Distal airway function in symptomatic subjects with normal spirometry following World Trade Center dust exposure. Chest 132(4):1275-1282, https://doi.org/10.1378/chest.07-0913.

Park JH, Kreiss K, Cox-Ganser JM [2012]. Rhinosinusitis and mold as risk factors for asthma symptoms in occupants of a water-damaged building. Indoor Air 22(5):396-404, https://doi. org/10.1111/j.1600-0668.2012.00775.x.

Parkes WR [1983]. Occupational lung disorders. London Butterworths: 359-453.

Pellegrino R, Viegi G, Brusasco V, Crapo RO, Burgos F, Casaburi R, Coates A, van der Grinten CP, Gustafsson P, Hankinson J, Jensen R, Johnson DC, MacIntyre N, McKay R, Miller MR, Navajas D, Pedersen OF, Wanger J [2005]. Interpretative strategies for lung function tests. Eur Respir J 26(5):948-968, https://doi.org/10.1183/09031936.05.00035205.

Penn A, Murphy G, Barker S, Henk W, Penn L [2005]. Combustion-Derived Ultrafine Particles Transport Organic Toxicants to Target Respiratory Cells. Environ Health Perspect 113(8):956-963, https://doi.org/10.1289/ehp.7661.

Quirce S [2004]. Eosinophilic bronchitis in the workplace. Curr Opin Allergy Clin Immunol. 4:87-91.

Rondón C, Campo P, Galindo L, Blanca-López N, Cassinello MS, Rodriguez-Bada JL, Torres MJ, Blanca M [2012]. Prevalence and clinical relevance of local allergic rhinitis. Allergy. 67(10):1282-1288, https://doi.org/10.1111/all.12002.

Sahay S, Gera K, Bhargava SK, Shah A [2016]. Occurrence and impact of sinusitis in patients with asthma and/or allergic rhinitis. J Asthma 53(6):635-643, https://doi.org/10.3109/ $\underline{02770903.2015 .1091005 .}$

Schermer TR, Malbon W, Morgan M, Smith M, Crockett AJ [2014]. Chronic respiratory conditions in a cohort of metropolitan fire-fighters: associations with occupational exposure and quality of life. Int Arch Occup Environ Health 87(8):919-928, https://doi.org/10.1007/ s00420-014-0935-8.

Schwartz J, Dockery DW, Neas LM [1996]. Is daily mortality associated specifically with fine particles? J Air Waste Manag Assoc 46(10):927-939, https://doi.org/10.1080/10473289.1 996.10467528.

Shaaban R, Zureik M, Soussan D, Neukirch C, Heinrich J, Sunyer J, Wjst M, Cerveri I, Pin I, Bousquet J, Jarvis D, Burney PG, Neukirch F, Leynaert B [2008]. Rhinitis and onset of asthma: a longitudinal population-based study. Lancet. 372(9643):1049-1057, https://doi. org/10.1016/S0140-6736(08)61446-4. 
Smith HJ, Reinhold P, Goldman MD [2005]. Forced oscillation technique and impulse oscillometry. In: Gosselink R, Stam H, eds. European Respiratory Monograph 31: Lung Function Testing. Vol. 10. Wakefield, UK: European Respiratory Society Journals, pp. 72105, https://pdfs.semanticscholar.org/b170/83a9fdfb2ffbca9765cfaf50a5a927ccf17f.pdf.

Smith HJ [2015]. Questions about impulse oscillometry. Email to Rachel Bailey, December 9.

Sparks PJ, Smith TJ, Fine LJ, Treitman RD, Spiegelman DL [1982]. Respiratory morbidity among processing and mill workers. A cross-sectional survey in three tire-manufacturing plants. J Occup Med 24:690-695.

Tarlo SM [1992]. Occupational asthma induced by tall oil in the rubber tyre industry. Clin Exp Allergy 22(1):99-101, https://doi.org/10.1111/j.1365-2222.1992.tb00120.x.

Thapa N, Tomasi SE, Cox-Ganser JM, Nett RJ [2019]. Non-malignant respiratory disease among workers in the rubber manufacturing industry: A systematic review and meta-analysis. Am J Ind Med 62(5):367-384, https://doi.org/10.1002/ajim.22959.

Thomas RJ, Bascom R, Yany WN, Fisher JF, Baser ME, Greenhut J, Baker JH [1986]. Peripheral eosinophilia and respiratory symptoms in rubber injection press operators: a casecontrol study. Am J Ind Med 9:551-559.

Togias A [2003]. Rhinitis and asthma: evidence for respiratory system integration. J Allergy Clin Immunol 111:1171-1183, https://doi.org/10.1067/mai.2003.1592.

Torén K, Blanc PD [2009]. Asthma caused by occupational exposures is common - A systematic analysis of estimates of the population-attributable fraction. BMC Pulmonary Med 9:7-7, https://doi.org/10.1186/1471-2466-9-7.

Vestbo J, Hurd SS, Agusti AG, Jones PW, Vogelmeier C, Anzueto A, Barnes PJ, Fabbri LM, Martinez FJ, Nishimura M, Stockley RA, Sin DD, Rodriguez-Roisin R [2013]. Global Strategy for the Diagnosis, Management, and Prevention of Chronic Obstructive Pulmonary Disease. GOLD Executive Summary. Am J Respir Crit Care Med 187(4): 347-365, https:// doi.org/10.1164/rccm.201204-0596PP.

Vogel J, Smidt U [1994]. Impulse oscillometry. Analysis of lung mechanics in general practice and clinic, epidemiological and experimental research. 1st ed. Frankfurt: PMIVerlagsgruppe.

Volcheck GW [2004]. Does rhinitis lead to asthma? Evidence for the one-airway hypothesis. Postgrad Med 115:65-68, https://doi.org/10.3810/pgm.2004.05.1507.

Weeks JL, Peters JM, Monson RR [1981a]. Screening for occupational health hazards in the rubber industry. Part I. Am J Ind Med 2(2):125-141, https://doi.org/10.1002/ ajim.4700020207. 
Weeks JL, Peters JM, Monson RR [1981b]. Screening for occupational health hazards in the rubber industry. Part II: Health hazards in the curing department. Am J Ind Med 2(2):143151, https://doi.org/10.1002/ajim.4700020208.

Zeliger HI [2003]. Toxic effects of chemical mixtures, Archives of Environmental Health. An International Journal 58(1):23-29, https://doi.org/10.3200/AEOH.58.1.23-29.

Zeliger HI [2011]. Human Toxicology of Chemical Mixtures: Toxic consequences beyond the impact of one-component product and environmental exposures, 2nd edition, Elsevier, NYC, NY.

Zuskin E, Mustajbegovic J, Schachter EN, Doko-Jelinic J, Budak A [1996]. Longitudinal study of respiratory findings in rubber workers. Am J Ind Med 30(2):171-179, https://doi. org/10.1002/(SICI)1097-0274(199608)30:2\%3C171::AID-AJIM8\%3E3.0.CO;2-3. 
This page left intentionally blank 
Keywords: NAICS 326299 (Manufacturing), Indiana, rubber, rubber manufacturing, volatile organic compounds, respiratory disease, chronic obstructive pulmonary disease, asthma. 
The Health Hazard Evaluation Program investigates possible health hazards in the workplace under the authority of the Occupational Safety and Health Act of 1970 (29 U.S.C. § 669(a)(6)). The Health Hazard Evaluation Program also provides, upon request, technical assistance to federal, state, and local agencies to investigate occupational health hazards and to prevent occupational disease or injury. Regulations guiding the Program can be found in Title 42, Code of Federal Regulations, Part 85; Requests for Health Hazard Evaluations (42 CPR Part 85).

\section{Disclaimer}

The recommendations in this report are made on the basis of the findings at the workplace evaluated and might not be applicable to other workplaces.

Mention of any company or product in this report does not constitute endorsement by the National Institute for Occupational Safety and Health (NIOSH).

Citations to Web sites external to NIOSH do not constitute NIOSH endorsement of the sponsoring organizations or their programs or products. NIOSH is not responsible for the content of these Web sites. All Web addresses referenced in this document were accessible as of the publication date.

\section{Acknowledgments}

Desktop Publisher: Barbara Elbon

Data Analysis Support: Nicole Edwards, Kathleen Fedan, and Brian Tift

Site Visit Team Members: Barbara Alexander, Rachel Bailey, Feng Chiao Su, Randall Nett, JuHyeong Park, Suzanne Tomasi

Medical Survey Team Members: Rachel Baily, Mike Beaty, Randy Boylstein, Diana Cale, Sophia Chiu, Katelynn Dodd, Nicole Edwards, Ethan Fechter-Leggett, Kathleen Fedan, Diana Freeland, Shilpa Gowda, Reid Harvey Randall Nett, Laura Reynolds, Suzanne Tomasi, and Brian Tift Ventilation Team Members: Mike Beaty, Feng Chia Su, Stephen Martin, Tia McCelland, Dylan Neu, and Marcia Stanton

Technical Support: Jean Cox-Ganser, Kristin Cummings, Steve Game, Michele Tennant, Brian Tift

\section{Availability of Report}

Copies of this report have been sent to the employer, employees, and union at the facility. The state and local health department and the Occupational Safety and Health Administration Regional Office have also received a copy. This report is not copyrighted and may be freely reproduced.This report is available at http://www.cdc.gov/niosh/hhe/reports/pdfs/2016-0227-3364.pdf.

All other Health Hazard Evaluation Reports may be found at http://www2a.cdc.gov/hhe/search.asp.

\section{Recommended citation for this report:}

NIOSH [2019]. Health hazard evaluation report: Evaluation of exposures and respiratory health at a rubber manufacturing facility. By Tomasi SE, Park J-H, Nett RJ, Martin Jr SB, Bailey RL, Cox-Ganser JM. Morgantown, WV: U.S. Department of Health and Human Services, Centers for Disease Control and Prevention, National Institute for Occupational Safety and Health, NIOSH HHE Report No. 2016-0227-3364 
Delivering on the Nation's promise:

Safety and health at work for all people through research and prevention

To receive documents or other information about occupational safety and health topics, contact NIOSH

Telephone: 1-800-CDC-INFO (1-800-232-4636)

TTY: 1-888-232-6348

email: cdcinfo@cdc.gov

or visit the NIOSH website at http://www.cdc.gov/niosh

SAFER • HEALTHIER • PEOPLE ${ }^{\text {TM }}$ 